ArgOn national laboratory

ANL-AFCI-132

\title{
Follow-up Analyses for the ANTT Review
}

Nuclear Engineering Division 


\section{About Argonne National Laboratory}

Argonne is a U.S. Department of Energy laboratory managed by The University of Chicago

under contract W-31-109-Eng-38. The Laboratory's main facility is outside Chicago, at

9700 South Cass Avenue, Argonne, Illinois 60439. For information about Argonne,

see www.anl.gov.

\section{Availability of This Report}

This report is available, at no cost, at http://www.osti.gov/bridge. It is also available

on paper to the U.S. Department of Energy and its contractors, for a processing fee, from:

U.S. Department of Energy

Office of Scientific and Technical Information

P.O. Box 62

Oak Ridge, TN 37831-0062

phone (865) 576-8401

fax (865) 576-5728

reports@adonis.osti.gov

\section{Disclaimer}

This report was prepared as an account of work sponsored by an agency of the United States Government. Neither the United States Government nor any agency thereof, nor The University of Chicago, nor any of their employees or officers, makes any warranty, express or implied, or assumes any legal liability or responsibility for the accuracy, completeness, or usefulness of any information, apparatus, product, or process disclosed, or represents that its use would not infringe privately owned rights. Reference herein to any specific commercial product, process, or service by trade name, trademark, manufacturer, or otherwise, does not necessarily constitute or imply its endorsement, recommendation, or favoring by the United States Government or any agency thereof. The views and opinions of document authors expressed herein do not necessarily state or reflect those of the United States Government or any agency thereof, Argonne National Laboratory, or The University of Chicago. 


\section{Follow-up Analyses for the ANTT Review}

by

J. A. Stillman, T. H. Bauer, R. N. Hill, and R. A. Wigeland

Nuclear Engineering Division, Argonne National Laboratory

September 30, 2004

work sponsored by

U. S. Department of Energy,

Office of Nuclear Energy, Science and Technology

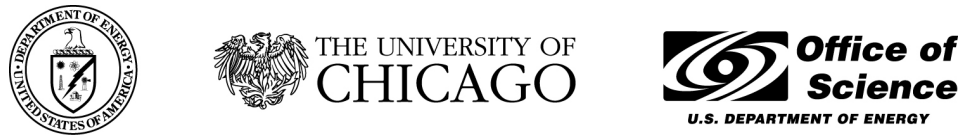

A U.S. Department of Energy laboratory managed by The University of Chicago 
(This page intentionally left blank) 


\section{INTRODUCTION}

Early in FY04, the Advanced Nuclear Transformation Technology (ANTT) subcommittee of the Nuclear Energy Research Advisory Committee (NERAC) requested a report on repository benefits for recycling of key transuranics in existing light watercooled reactors (LWRs). The ANTT reviewers specifically requested a quantification of how such a campaign would impact (improve) the achievable loading of nuclear waste in the Yucca Mountain facility. The request stipulated that the transuranics be separated from commercial spent nuclear fuel (CSNF) and recycled a finite number of times in LWR-compatible fuel forms. The spent fuel remaining at the end of the recycling campaign, as well as all other nuclear waste generated by spent fuel reprocessing, would be permanently disposed in a geologic repository.

In response, two reports have been prepared and distributed as deliverables for the AFCI program. Reference 1 provides the final report which addresses the original ANTT sub-committee request. Plutonium, neptunium, and americium recycling strategies in assemblies fabricated from mixed-oxide (MOX), CORAIL (heterogeneous $\mathrm{UO}_{2}$ and MOX), and inert-matrix fuel (IMF) forms were evaluated; the focus of the report is the time-dependent thermal response of the repository to a given loading of nuclear waste in the storage tunnels (drifts), as well as a quantification of how the loading could be increased relative to the reference direct disposal of CSNF. Reference 2 provides a more complete description of the neutronics and mass flow analyses which were completed as part of the study. That report also provides an analysis of the differences between the various recycling strategies and the underlying reactor physics.

Subsequent to the original request, a variety of follow-up questions have been posed either directly by the ANTT committee members or as a natural outgrowth of the study. Analytical studies were conducted to assess some of the key inquiries:

1. What is the isotopic vector of the transuranics in spent $\mathrm{UO}_{2}$, and how is it affected by post-irradiation cooling time? How is the recycling strategy impacted by cooling time? (Section II)

2. What is the impact of cooling time before spent fuel disposal or reprocessing on the calculated repository loading of nuclear waste? (Section III)

3. Is there any increase in the proliferation resistance of the separated transuranics due to recycling? (Section IV)

4. What are the fast reactor resource requirements to support thermal $\mathrm{UO}_{2}$ power production? What is the impact of thermal recycle? How does the repository benefit from fast reactor recycle compare to limited thermal recycle results? (Section V)

Questions 1 and 2 rely heavily on the detailed analysis work in Refs. 1 and 2, but the new results related to extended cooling time are highlighted in Sections II and III, respectively. Section IV provides a brief analysis of the proliferation resistance of separated plutonium from various sources. The fast reactor nuclear enterprise energy requirements and limited recycle benefits are addressed in Section V. Section VI discusses further issues which have not yet been fully addressed within the AFCI program, but are topics for future analyses. 


\section{LWR RECYCLE STRATEGIES AND IMPACT OF COOLING TIME}

In the repository benefits analysis conducted for the ANTT request, it was assumed that the spent LWR fuel would be reprocessed after 5 years post-irradiation cooling, the earliest time at which spent fuel processing is practically considered. The transuranic material in the first recycle in MOX or IMF fuel was assumed harvested from $\mathrm{UO}_{2}$ which had been enriched to $4.3 \mathrm{wt} . \% \mathrm{U}-235$ and irradiated to $51 \mathrm{GWd} / \mathrm{MT}$. The isotopic vector for the transuranics is provided in Table II.1; alternate vectors if harvesting is performed at 10 and 20 years cooling are also provided.

Section III deals with the consequences of longer cooling times on direct disposal or reprocessing/recycling strategies with regard to the achievable repository loading of nuclear waste. The remainder of this section focuses on practical LWR recycle strategies currently under consideration in the AFCI program, with a particular emphasis on how cooling time impacts fuel fabrication and handling.

Table II.1. Transuranic Isotopic Vector (wt.\%) in Spent $\mathrm{UO}_{2}$ (51 GWd/MT).

\begin{tabular}{|c|c|c|c|}
\hline \multirow{2}{*}{} & \multicolumn{3}{|c|}{ Number of Years Cooled } \\
\cline { 2 - 4 } & $\mathbf{5}$ Years & $\mathbf{1 0}$ Years & $\mathbf{2 0}$ Years \\
\hline \hline $\mathrm{Np}-237$ & $4.76 \%$ & $4.76 \%$ & $4.77 \%$ \\
\hline $\mathrm{Pu}-238$ & $2.36 \%$ & $2.27 \%$ & $2.11 \%$ \\
\hline $\mathbf{P u}-239$ & $\mathbf{4 7 . 6 5 \%}$ & $\mathbf{4 7 . 6 9 \%}$ & $\mathbf{4 7 . 7 8 \%}$ \\
\hline $\mathrm{Pu}-240$ & $22.54 \%$ & $22.65 \%$ & $22.81 \%$ \\
\hline $\mathbf{P u}-241$ & $\mathbf{1 0 . 6 1 \%}$ & $\mathbf{8 . 3 5 \%}$ & $\mathbf{5 . 1 7 \%}$ \\
\hline $\mathrm{Pu}-242$ & $6.61 \%$ & $6.61 \%$ & $6.63 \%$ \\
\hline $\mathrm{Am}-241$ & $3.38 \%$ & $5.65 \%$ & $8.86 \%$ \\
\hline $\mathrm{Am}-243$ & $1.51 \%$ & $1.51 \%$ & $1.51 \%$ \\
\hline $\mathrm{Cm}-244$ & $0.54 \%$ & $0.44 \%$ & $0.30 \%$ \\
\hline $\mathbf{C m}-245$ & $\mathbf{0 . 0 4 \%}$ & $\mathbf{0 . 0 4} \%$ & $\mathbf{0 . 0 4} \%$ \\
\hline
\end{tabular}

\section{II.1. Challenges to Transuranic Recycling In LWRs}

Fissile nuclides are indicated by bold type-face in Table II.1. These are consumed quite readily in thermal-spectrum reactors. The remaining nuclides (comprising $42 \%$ or more of the transuranics, depending on the cooling time) must first be transformed into fissile nuclides through neutron interactions before they can be truly consumed in the thermal neutron spectrum. This represents one of the primary challenges of transuranic recycling in LWRs: as the fissile content of the recycled fuel declines either by their consumption or radioactive decay (Pu-241 to Am-241), there is an insufficient number of neutrons to maintain a self-sustaining chain reaction and transform the non-fissile nuclides. 
There has been significant research the last few years both abroad (particularly CEA) and in the AFCI program to develop practical strategies for multiple recycle in conventional LWRs. Although dedicated schemes using only recycled materials in LWRs still appear to be impractical, a variety of fuel management strategies for including the recycled materials in conjunction with standard fuel materials (LEU) have been developed. The consensus of these recent studies is that continuous recycle in LWRs can be achieved within two important constraints:

1. an external fissile feed (e.g., LEU) is required to "support" the transmutation

2. a technique to manage the higher actinides ( $\mathrm{Cm}$ and above) must be employed.

Both of these issues are attributed to the physics of actinide fission and transmutation in a thermal spectrum. Because the neutron balance for the recovered transuranics (TRU) is not favorable enough to sustain the reactor, external support is required. For example, in the CORAIL concept $\sim 2 / 3$ of the pins are LEU enriched slightly beyond normal fuel (to roughly 5\% U-235/U) which "drive" the 1/3 MOX pins. Initial work demonstrated that it is possible to recycle all TRU in the CORAIL concept with the $5 \%$ enrichment LEU pins and MOX pins at equilibrium enrichments of 23\% TRU/HM (significantly higher than for separated plutonium recycle). ${ }^{3}$

While feasible from a neutronics viewpoint, an LWR recycle approach using full transuranic recycle does present challenges in regard to fuel handling. This is illustrated in Table II.2, which summarizes heat and radiation sources for CORAIL fuel materials at equilibrium enrichments when various transuranic elements are recycled. A build-up of higher actinides results from the relatively high capture-to-fission ratios for non-fissile nuclides in a thermal spectrum. Although initial recycles may be possible, eventually very high actinides (e.g., Cf-252) will build in and make the fuel quite difficult to handle. For example, the neutron source at equilibrium when recycling all transuranic species is more than four orders of magnitude larger than that observed for the more conventional MOX forms (indicated approximately by the CORAIL-Pu results in Table II.2), although this can be mitigated somewhat by allowing a longer cooling period before recycling the transuranics back into the reactor, which allows for the decay of Cm-244 and Cf-252 (half-lives of 18.1 and 2.6 years, respectively). Likewise, recycling only select actinides in the LWR fuel cycle will limit the buildup of the fuel handling indices.

The radio-isotopic properties provided in Table II.3 give a measure of the fuel handling impact at the fabrication plant or reactor site when particular actinide species are recycled. The heat and radiation sources for the uranium isotopes are quite low compared to other actinides, and for this reason fuel handling procedures developed for current U. S. nuclear power plants allow for contact handling of the fabricated $\mathrm{UO}_{2}$ assemblies, as well as lower shielding requirements than required for mixed-oxide (MOX) fuel.

It was reported in Ref. 4 that the decay heat for a typical MOX assembly fabricated with plutonium is around 800 watts (compared with $0.03 \mathrm{~W}$ for a $\mathrm{UO}_{2}$ assembly), and that most of this heat comes from Pu-238. Thus, it is desirable to limit the assembly loading of Pu-238, particularly if special post-fabrication assembly storage is to be avoided. According to the data presented in Table II.3, recycling Cm-244 presents an 
Table II.2. Comparison of Equilibrium State Radiation Parameters for CORAIL Fuel Materials. ${ }^{a}$

\begin{tabular}{|c|c|c|c|c|c|c|}
\hline \multirow{2}{*}{\multicolumn{2}{|c|}{\begin{tabular}{|l} 
Species Recycled \\
Cooling time (years)
\end{tabular}}} & \multirow{3}{*}{$\begin{array}{l}\text { Pu } \\
5 \\
1,960\end{array}$} & \multirow{2}{*}{$\frac{\text { Pu-Np }}{5}$} & \multirow{2}{*}{$\frac{\text { Pu-Np-Am }}{5}$} & \multicolumn{2}{|c|}{ All TRU } \\
\hline & & & & & 5 & 20 \\
\hline \multirow{4}{*}{$\begin{array}{l}\text { Decay } \\
\text { Heat } \\
\text { (Watt) }\end{array}$} & Fabrication $^{b}$ & & 3,766 & 11,600 & 38,390 & 25,520 \\
\hline & Charge $^{\mathrm{c}}$ & 655 & 1,249 & 3,788 & 11,930 & 8,278 \\
\hline & Discharge $^{d}$ & $2.00 \mathrm{E}+6$ & $2.01 \mathrm{E}+6$ & $1.99 \mathrm{E}+6$ & $2.00 \mathrm{E}+6$ & $2.01 \mathrm{E}+6$ \\
\hline & $\begin{array}{l}\text { After } \\
\text { cooling }\end{array}$ & 4,404 & 4,924 & 9,551 & 14,520 & 9,118 \\
\hline \multirow{4}{*}{$\begin{array}{l}\text { Neutron } \\
\text { Source } \\
\text { (n/sec) }\end{array}$} & Fabrication & $1.20 \mathrm{E}+8$ & $1.84 \mathrm{E}+8$ & $4.60 \mathrm{E}+8$ & $7.65 E+12$ & $2.45 E+11$ \\
\hline & Charge & $3.96 \mathrm{E}+7$ & $6.05 \mathrm{E}+7$ & $1.50 \mathrm{E}+8$ & $1.51 \mathrm{E}+12$ & $6.22 \mathrm{E}+10$ \\
\hline & Discharge & $9.59 \mathrm{E}+9$ & $9.45 \mathrm{E}+9$ & $2.50 \mathrm{E}+10$ & $9.08 \mathrm{E}+12$ & $1.25 \mathrm{E}+13$ \\
\hline & After cooling & $6.36 \mathrm{E}+9$ & $6.00 \mathrm{E}+9$ & $1.51 \mathrm{E}+10$ & $2.51 \mathrm{E}+12$ & $1.07 E+11$ \\
\hline \multirow{4}{*}{$\begin{array}{l}\text { Gamma } \\
\text { Source }^{e} \\
\text { (Watt) }\end{array}$} & Fabrication & 0.57 & 1.08 & 7.79 & 23.30 & 20.67 \\
\hline & Charge & 0.32 & 0.51 & 2.73 & 7.10 & 9.13 \\
\hline & Discharge & 547,725 & 549,022 & 538,192 & 533,898 & 533,738 \\
\hline & After cooling & $1,030.14$ & $1,020.30$ & 982.25 & 978.56 & 344.39 \\
\hline
\end{tabular}

${ }^{a}$ Data in this table taken from Ref. 5.

${ }^{\mathrm{b}}$ The fabrication stage data is for one metric ton of MOX pin.

${ }^{\mathrm{C}}$ Charge data is based on one metric ton of heavy-metal (U and TRU) present in the charge assembly.

${ }^{\mathrm{d}}$ Data for discharge and after cooling (five or 20 years) are based on the resulting mass after irradiation ( 0.954 ton in all cases). The discharge and five (or 20) year after discharge (after cooling) data include contributions from fission products.

${ }^{\mathrm{e}} \mathrm{Gamma}$ source is expressed in equivalent $\mathrm{MeV} / \mathrm{s}$ (or watts), as a means of providing indications of the relative unshielded gamma dose rates. This approach does not capture the overall gamma dose, however, particularly for shielded situations.

Table II.3. Radio-Isotopic Properties for One Gram of Selected Actinides.

\begin{tabular}{|l|c|c|c|c|c|}
\hline & \multirow{2}{*}{$\begin{array}{c}\text { Half-Life } \\
\text { (years) }\end{array}$} & \multirow{2}{*}{$\begin{array}{c}\text { Decay Heat } \\
\text { (Watts) }\end{array}$} & \multicolumn{2}{|c|}{$\begin{array}{c}\text { Neutron Source } \\
\text { (neutrons/s) }\end{array}$} & \multirow{2}{*}{$\begin{array}{c}\gamma \text { Source } \\
\text { (MeV/s) }\end{array}$} \\
\cline { 4 - 5 } & & & $\mathbf{( \alpha , n )} \mathbf{1}^{\mathbf{1}}$ & $\begin{array}{c}\text { Spontaneous } \\
\text { Fission }\end{array}$ & \\
\hline U-235 & $7.04 \mathrm{E}+8$ & $5.7 \mathrm{E}-8$ & $7.91 \mathrm{E}-4$ & $3.53 \mathrm{E}-4$ & $1.24 \mathrm{E}+4$ \\
\hline U-238 & $4.47 \mathrm{E}+9$ & $8.5 \mathrm{E}-9$ & $1.06 \mathrm{E}-4$ & 0.013 & $1.47 \mathrm{E}+1$ \\
\hline Np-237 & $2,140,000$ & $2.2 \mathrm{E}-5$ & 0.50 & 0.0 & $8.80 \mathrm{E}+5$ \\
\hline Pu-238 & 87.7 & 0.568 & 16,290 & 2,657 & $1.01 \mathrm{E}+9$ \\
\hline Pu-239 & 24,100 & 0.002 & 45.30 & 0.023 & $1.44 \mathrm{E}+6$ \\
\hline Pu-240 & 6,560 & 0.007 & 172.7 & 910.5 & $1.29 \mathrm{E}+7$ \\
\hline Pu-241 & 14.4 & 0.003 & 0.0 & 0.0 & $1.45 \mathrm{E}+7$ \\
\hline Am-241 & 433 & 0.114 & 3,293 & 1.24 & $3.10 \mathrm{E}+9$ \\
\hline Am-243 & 7,370 & 0.006 & 170.1 & 3.35 & $4.07 \mathrm{E}+8$ \\
\hline Cm-244 & 18.1 & 2.831 & 92,360 & $11,120,000$ & $4.58 \mathrm{E}+9$ \\
\hline Cf-252 & 2.65 & 38.40 & 636,300 & $2.3 \mathrm{E}+12$ & $7.88 \mathrm{E}+12$ \\
\hline
\end{tabular}

${ }^{1}$ Calculated by ORIGEN2 assuming material in an oxide matrix. 
even greater challenge. If the above MOX assembly included just 250 grams Cm-244 (a concentration of $\sim 0.7 \%$ of the TRU mass), the fabricated assembly would produce the same heat as a spent $\mathrm{UO}_{2}$ assembly after 5 years cooling $(\sim 1.5 \mathrm{~kW})$.

Radiation dose to fuel handling workers is a greater consideration for transuranicbearing fuels. Photon dose rates from unirradiated MOX fuel assemblies fabricated with plutonium are significantly higher than those from $\mathrm{UO}_{2}$, but are manageable without altering fuel handling equipment at the reactor site. Indeed, the fuel cladding provides significant shielding against the lower-energy photons emitted by Pu-238 and, to a lesser extent, those emitted by Am-241. Because of the higher photon energy source from Am241, it can be expected that a limit will be placed on the Am-241 concentration in the MOX material at the fabrication facility. For example, the Am-241 concentration at the French MELOX plant is limited to $<3 \% \mathrm{Am}-241 / \mathrm{Pu}$ to prevent excess radiation exposure to workers.

The photon source/gram is also high for $\mathrm{Cm}-244$, but as for Pu-238, these are very low energy photons which are relatively easy to shield. A much larger dose contribution results from the extremely high neutron source from spontaneous fission, which is more difficult to shield against. Furthermore, if the curium is multi-recycled in the LWR, the buildup of very high mass actinides (i.e., Cf-252) in even minute quantities results in a neutron source rate that is more than four orders of magnitude larger than that for conventional MOX fabricated from plutonium only, as already shown in Table II.2.

Thus, it is envisioned that the relative concentrations of Pu-238, Am-241, and Cm244 in the fuel must be controlled to limit the radiation shielding requirements for workers at a fabrication facility. An identification of these limits could be the focus of future work. Furthermore, upgrading fuel handling equipment and/or practices at current reactor sites to accommodate curium recycling in LWRs with short cooling times would likely be prohibitively expensive.

\section{II.2. Transuranic Recycling Strategies for LWRs}

Steps must be taken to suppress the generation of the higher actinides in LWR recycle strategies. One approach, as taken in recent studies at Oak Ridge National Laboratory, is to interpose a long cooling time (40 years) to allow for decay of certain actinides, as well as problematic fission and activation products. It has been suggested that this approach will lower the capital and operating costs of a spent fuel reprocessing facility because of lower costs for waste treatment, disposal, and shielding. ${ }^{6}$ In this approach, the $\mathrm{Pu}+\mathrm{Np}$ are recycled in MOX fuel pins, while the $\mathrm{Am}+\mathrm{Cm}$ are transmuted in heterogeneous target rods (in more recent analyses the $\mathrm{Am}+\mathrm{Cm}$ are blended with $\mathrm{LEU}$ ). From a recycling perspective, the extensive decay of the Cm-244 (18.1 year half-life with decay back to $\mathrm{Pu}-240$ ) and the Pu-241 (14.4 year half-life with decay to Am-241, which is likely to bypass curium through Am-242 decay) will inhibit the production of higher actinides. Table II.2 showed that extending the cooling time from 5 years to 20 years with all TRUs recycled decreased the neutron source by a factor of 30, and additional cooling would derive a greater benefit. This approach will mitigate, but not eliminate, the generation of higher actinides, but significantly elevated decay heat and neutron sources levels (at least 100X) are still expected at equilibrium. Furthermore, the repository benefits of this 
heterogeneous recycling approach with long cooling times relative to homogenous recycling with short cooling times (described next) must still be evaluated.

Another approach to actinide management in LWRs is to remove the higher actinide elements in the separations process. This was the approach taken for the recent repository benefit analyses [Refs. 1 and 2], where the Cm (which accounts for $<0.6 \%$ of the TRU mass, and $<0.008 \%$ of the heavy metal in spent $\mathrm{UO}_{2}$ ) was removed and stored each recycle. As shown in the Pu-Np-Am column of Table II.2, this largely avoids the elevated neutron source, although increases in the decay heat and gamma source (of roughly an order of magnitude) are observed from the inclusion of Am. This strategy will incur the added expense of $\mathrm{Cm}$ separation particularly from Am and associated storage facility (unless the $\mathrm{Cm}$ stream can be directly disposed with the fission product wastes). However, it appears to be quite effective in preventing the generation of higher actinides. As an alternative to direct disposal or interim storage, the curium could be fabricated into dedicated targets for LWR transmutation or recycled in a fast spectrum system.

Increasing the cooling time before spent fuel reprocessing (and curium separation) reduces the fissile content of the recycled fuel due to the ongoing decay of $\mathrm{Pu}-241$ $\left(\mathrm{t}_{1 / 2}=14.4\right.$ years) to Am-241. For example, Table II.1 shows that waiting 20 years before reprocessing decreases the $\mathrm{Pu}-241$ content from $10.6 \%$ to $5.2 \%$, with an associated increase of Am-241 from 3.4\% to 8.9\%. Consequently, a higher transuranic loading is needed in the fabricated fuel to meet the irradiation cycle requirements. Likewise, a twoyear post-fabrication interval was assumed before the fuel was charged into the reactor; the length of this interval is also important, for the same reasons noted above. 


\section{IMPACT OF COOLING TIME BEFORE SPENT FUEL DISPOSAL OR REPROCESSING}

Previous work has already shown the benefits to a geologic repository of processing spent PWR fuel to remove plutonium, americium, curium, cesium, and strontium.[1,7,8,9,10] For the current analyses, the example of a geologic repository is still taken as the proposal for the design and operation of a repository at Yucca Mountain. The design specified a drift spacing of $81 \mathrm{~m}$, and a ventilation period of at least 50 years, although analyses were most often done with the extended ventilation period of 75 years. The current proposals for temperature limits in the high temperature operating mode (HTOM) of the cold repository were also used, including the limit of $96{ }^{\circ} \mathrm{C}$ between adjacent drifts to allow drainage of liquid water through the repository at all times, and a rock temperature limit of $200{ }^{\circ} \mathrm{C}$ to avoid altering the crystalline structure of the rock. Also, in most cases the spent fuel was assumed to be placed in the repository at an average age of 25 years.

The transient thermal behavior of the repository was calculated using the same detailed 3D model as used in the previous analyses. [11] From these analyses, it was determined that the loading of the repository was constrained by the temperature limits for the repository, and if an increased repository drift loading were desired (on a MTIHM basis), the chemical separation of plutonium and americium was required, which results in a drift loading increase of about 4-6. To further increase the drift loading, removal of cesium and strontium would result in a factor of about 40-50. The additional separation of curium further increased the factor to about 100. (As noted in the earlier work, there may be an issue as to whether or not waste forms are available or can be created that are able to take advantage of this very large increase in repository drift loading.)

Obviously, the need for, and the effect of, separations is determined by the specific design of the repository, the associated temperature limits, and the characteristics of the wastes proposed for disposal. The purpose of this study is to evaluate the impact of alternate repository design and operations choices for the disposal or processing of spent nuclear fuel.

\section{III.1. Direct Disposal of Spent Nuclear Fuel}

Delaying placement time will have an impact on the potential repository loading for the direct disposal of spent nuclear fuel. For the purposes of comparison with cases involving separations and recycling, the effect of only delaying placement of the spent fuel is examined first, followed by discussions of the recycling scenarios.

\section{III.1.a. $\quad$ Reference Case: Disposal at 25 Years After Spent Fuel Discharge}

Since the transient thermal behavior of the repository is determined by the decay heat of the emplaced materials, delaying placement to allow further cooling of these materials should have some benefit in allowing increased loading of the repository drifts. The repository behavior for the current reference of 25 year old spent fuel [12] is shown in Figure III.1, with the heat transfer paths shown in Figure III.2. The drift loading of 1.15 $\mathrm{MTIHM} / \mathrm{m}$ corresponds to the maximum allowable loading given the temperature limits 


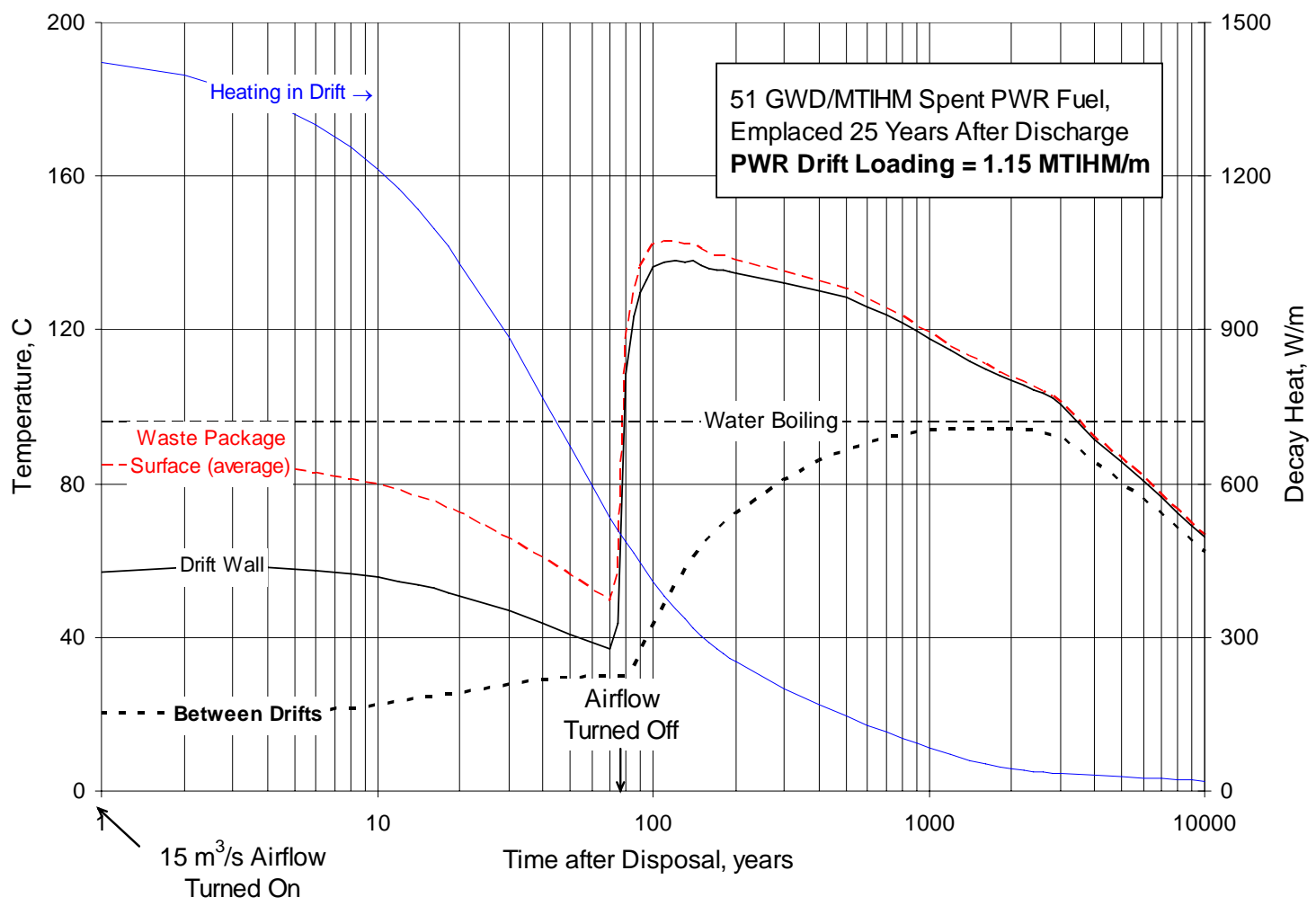

Figure III.1. Transient thermal behavior of a repository at Yucca Mountain for a drift in the central region of the repository; direct disposal of spent PWR fuel, 25 years after discharge.

cited above, without allowing any margin for uncertainties. The maximum loading does not necessarily represent loading planned for a repository at Yucca Mountain, but is useful for establishing relative benefits between options. As identified in the previous work, Figure III.1 clearly shows that drift loading is constrained by the temperature limit midway between adjacent drifts, $96{ }^{\circ} \mathrm{C}$, with the peak temperature in that region being reached at about 1600 years after disposal.

Figure III.2 indicates the effect of ventilation for removing most of the decay heat generated during the first 75 years after placement in the repository. The decay heat which contributes to reaching the temperature peak is mostly caused by the decay heat generated from 75 years after disposal out to about 1600 years. As described in the earlier work, this decay heat is caused mainly by Am-241, with some contributions from plutonium isotopes, and is the reason that these elements must be removed from the spent fuel first to provide any potential for increasing the repository drift loading.

\section{III.1.b. Impact of Delaying Placement, Extending Ventilation, and Reducing Drift Spacing}

Given the repository transient behavior described in the previous section, further analyses were performed where the spent nuclear fuel was allowed to cool for extended periods of time before being placed in the repository. The delay times selected were $50,75,100$, 


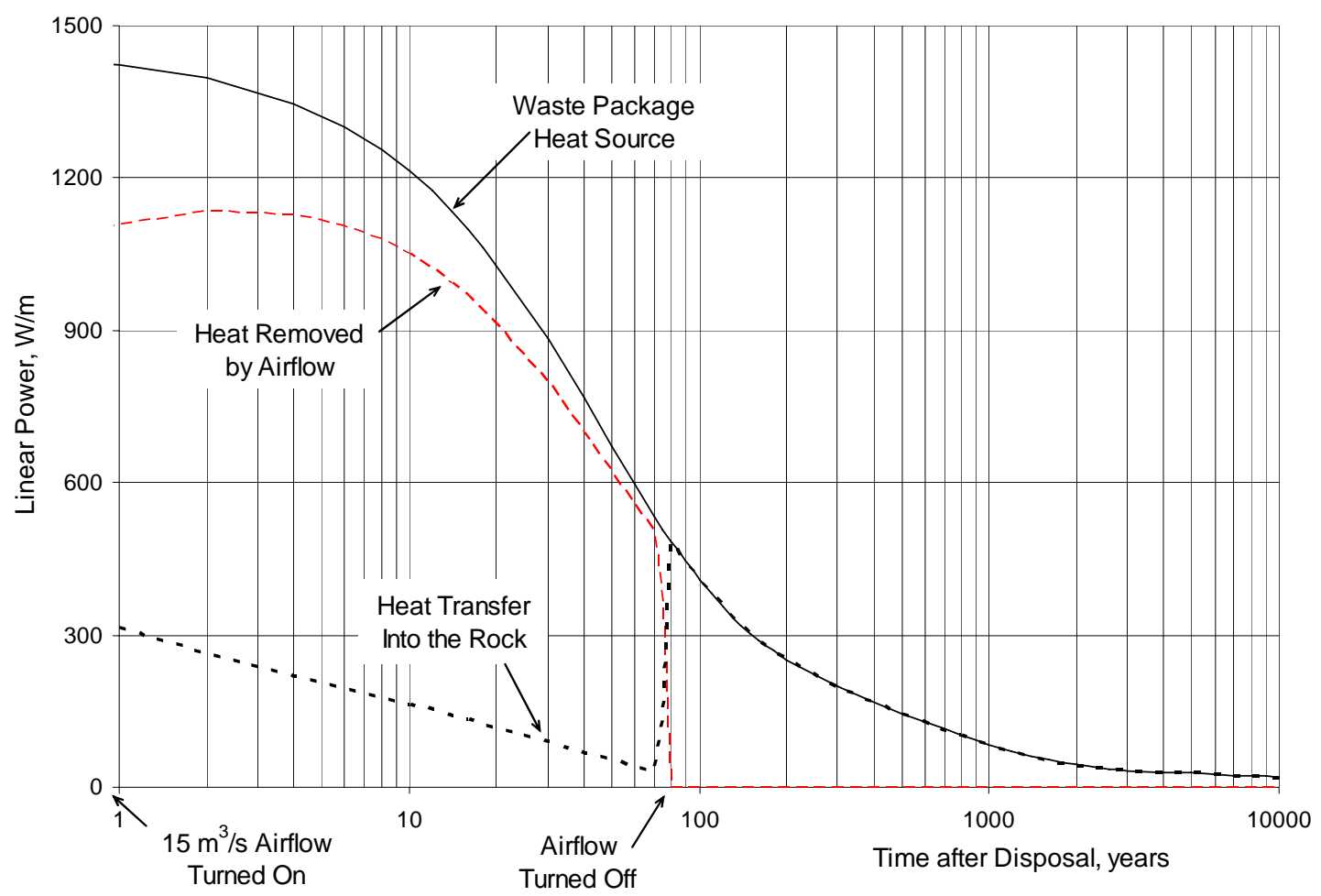

Figure III.2. Heat transfer paths in a repository at Yucca Mountain for a drift in the central region of the repository; direct disposal of spent PWR fuel, 25 years after discharge.

125, and 150 years after discharge from the reactor. In each case, the maximum drift loading was determined, consistent with the appropriate temperature limits. The allowable increases in drift loading are listed in Table III.1, and are due mainly to having more of the decay heat from $\mathrm{Pu}-238$ being removed during storage and ventilation prior to closure of the repository, with the result that the decay heat from closure out to the time of peak temperature midway between adjacent drifts is more heavily weighted to the longer-lived isotopes Am-241, Pu-240, and Pu-239.

For each case with a longer delay time, the transient behavior of the repository is similar to that already shown in Figure III.1, with the drift loading constrained by the peak temperature midway between adjacent drifts. Figure III.3 compares the decay heat generated after placement in the repository for the range of delay times studied. With progressively longer delay time before placement, the temperatures during the ventilation phase are correspondingly lower due to the lower decay heat, even with the higher drift loading. A ventilation period of 75 years is used in all cases. For example, the peak waste package temperature for the case with 25 year old spent fuel is $85{ }^{\circ} \mathrm{C}$ just after placement, while the peak waste package temperature is only $42{ }^{\circ} \mathrm{C}$ when the fuel has cooled for 150 years before placement, even at the higher loading listed in Table III.1.

Similarly, after the end of the ventilation phase, the peak temperatures achieved drops from about $140{ }^{\circ} \mathrm{C}$ for 25 year old fuel to about $125{ }^{\circ} \mathrm{C}$ for 150 year old fuel (placed at the higher loading indicated in Table III.1). However, the time where the area around the 
Table III.1. Maximum drift loading for direct disposal of spent PWR fuel.

\begin{tabular}{|l|l|l|l|}
\hline Delay Time & $\begin{array}{l}\text { Maximum Drift } \\
\text { Loading (MTIHM/m) }\end{array}$ & $\begin{array}{l}\text { Relative Drift } \\
\text { Loading Increase }\end{array}$ & $\begin{array}{l}\text { Limiting Temperature } \\
\left.\text { (Time }^{2}\right)\end{array}$ \\
\hline 25 years & 1.15 & 1.00 & $\begin{array}{l}\text { Midway between } \\
\text { drifts (1600 years) }\end{array}$ \\
\hline 50 years & 1.23 & 1.07 & $\begin{array}{l}\text { Midway between } \\
\text { drifts (1700 years) }\end{array}$ \\
\hline 75 years & 1.27 & 1.10 & $\begin{array}{l}\text { Midway between } \\
\text { drifts (1800 years) }\end{array}$ \\
\hline 100 years & 1.31 & 1.14 & $\begin{array}{l}\text { Midway between } \\
\text { drifts (1900 years) }\end{array}$ \\
\hline 125 years & 1.37 & 1.19 & $\begin{array}{l}\text { Midway between } \\
\text { drifts (2000 years) }\end{array}$ \\
\hline 150 years & 1.42 & 1.23 & $\begin{array}{l}\text { Midway between } \\
\text { drifts (2100 years) }\end{array}$ \\
\hline
\end{tabular}

${ }^{1}$ Relative drift loading increase comparing the maximum drift loading for the direct disposal of spent PWR fuel at longer delay times to the maximum drift loading for the direct disposal of spent PWR fuel with 25 years delay.

${ }^{2}$ Time estimated to the nearest 100 years.

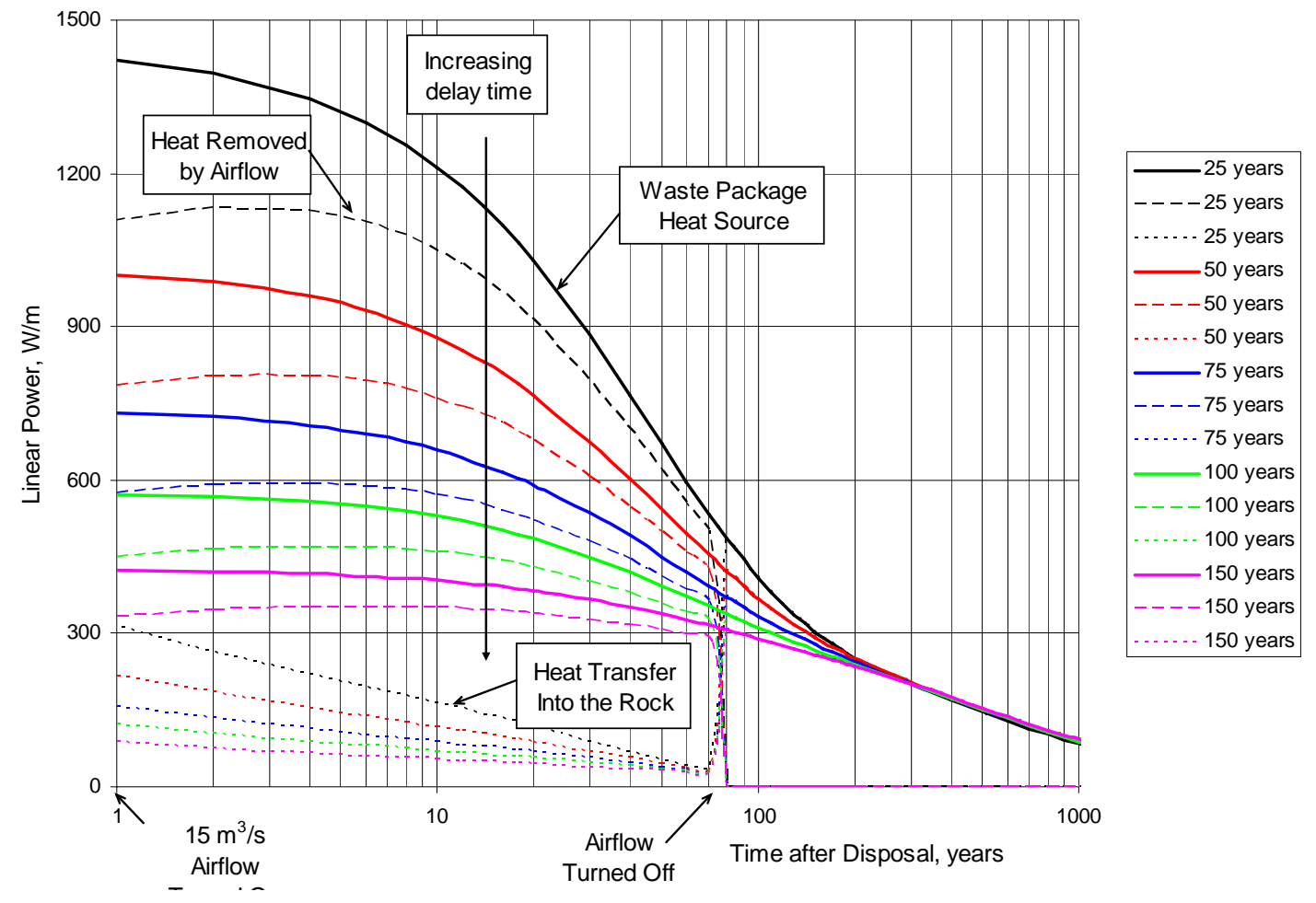

Figure III.3. Decay heat for the direct disposal of spent PWR fuel for a range of delay times prior to placement in the repository; maximum drift loading in each case; ventilation period of 75 years. 
drift is above the boiling point increases from about 3500 years with 25 year old spent fuel to 5000 years for 150 year old spent fuel. This is caused by the increased drift loading with decay heat dominated by longer lived actinide isotopes, which increases the linear heat load over the long term after the repository is closed, as shown in Figure III.4.

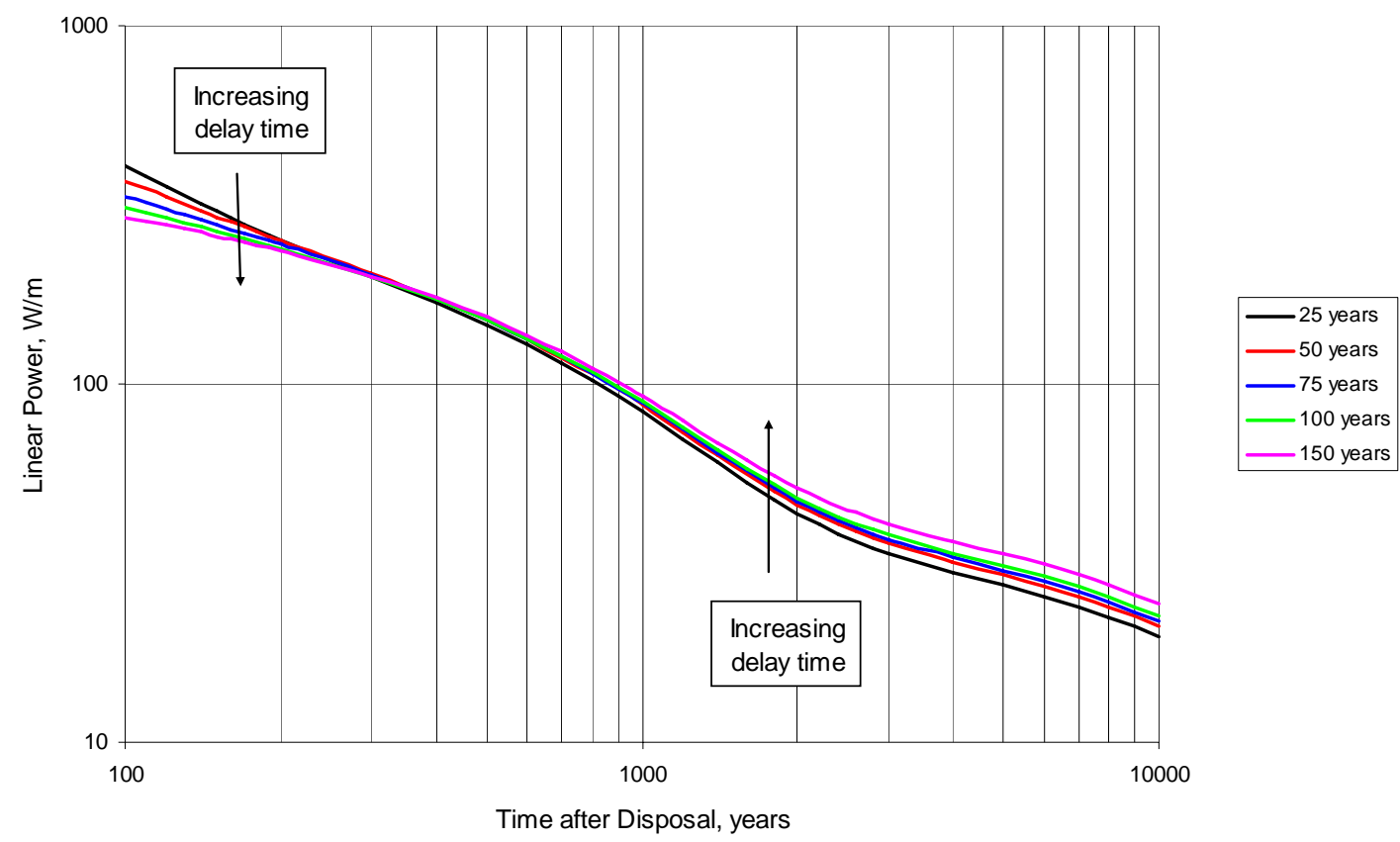

Figure III.4. Decay heat for the direct disposal of spent PWR fuel for a range of delay times prior to placement in the repository; post-closure period, maximum drift loading in each case.

The overall effect is that delaying placement in the repository results in a small increase in the maximum allowable repository drift loading. This is because the drift loading is constrained by the decay heat from americium and plutonium during the time period from closure of the repository out to about 1500-2000 years. As a consequence, even delays of up to 150 years have a relatively minor impact.

It should be noted that these results also apply to the case where the spent fuel is still placed at 25 years after discharge from the reactor, but the ventilation period is substantially extended, since most of the decay heat generated during the ventilation period is removed by the airflow. As an example, one would expect that the benefit of a ventilation period of 200 years after a cooling time of 25 years would be about 1.2, about the same as one would achieve from a cooling time of 150 years prior to placement, followed by 75 years of ventilation. Additionally, since in all of these cases, the repository drift loading is limited by the peak temperature midway between adjacent drifts, there is no opportunity to alter the drift spacing from the reference value of $81 \mathrm{~m}$. 


\section{III.2. Effect of Delaying Spent Fuel Reprocessing With Limited Recycling of Transuranics}

Since Am-241 is the primary contributor to the decay heat of disposed reactor-grade TRU in the time-frame of interest for repository heating (100-1500 years), and this is created by the decay of $\mathrm{Pu}-241$ during storage, processing the spent nuclear fuel as soon as possible after discharge is preferred. Fro the same reason, LWR transmutation strategies target the destruction of Pu-241 and Am-241 to reduce the amount of Am-241 chain nuclides disposed in the repository waste. While Pu-241 is primarily destroyed by fission, $\sim 75 \%$ of neutron absorptions in Am-241 yield $\mathrm{Pu}-238$, which, while not as problematic as the Am-241, still contributes to the repository heating. Since the ongoing decay of $\mathrm{Pu}-$ 241 prior to reprocessing (or following fabrication of fresh MOX or IMF) increases the relative fraction of Am-241 in the recycled TRU, it is preferable from the perspective of reducing the repository heating to process and recycle the $\mathrm{Pu}-241 \mathrm{back}$ into the reactor as soon as practical. Furthermore, higher enrichments are needed when older fuel is processed and recycled due to the decay of fissionable isotopes and the increase in isotopes that are more likely to capture neutrons in the thermal spectrum. The higher enrichment increases both the Pu-239 and Pu-240 content in the recycled fuel, and the net production of Pu-241 is increased, potentially reducing the benefit to the repository from processing and recycling spent fuel.

After five years, the spent fuel has cooled sufficiently to allow aqueous reprocessing (e.g., UREX+), but longer cooling times might be preferred in practice to balance reprocessing and fabrication mass flows. In order to assess the impact of longer cooling intervals on the repository benefit, calculations were also performed assuming 20 years postirradiation cooling before spent $\mathrm{UO}_{2}$ reprocessing, followed by a single recycle of plutonium, neptunium, and americium in an LWR. The results are summarized in Table III.2.

Table III.2. Repository drift loading increase factors for one recycle using MOX, CORAIL-PNA, and IMF with spent PWR fuel processed at 5 years and at 20 years.

\begin{tabular}{|l|c|c|}
\hline Fuel Form & $\begin{array}{c}\text { 5 Year Old Spent } \\
\text { PWR Fuel }\end{array}$ & $\begin{array}{c}\text { 20 Year Old Spent } \\
\text { PWR Fuel }\end{array}$ \\
\hline MOX & 1.09 & 1.04 \\
\hline CORAIL-PNA & 1.22 & 1.16 \\
\hline IMF & 1.79 & 1.19 \\
\hline
\end{tabular}

As is shown in the table, the effect of processing older fuel and recycling the recovered plutonium, americium, and neptunium in an LWR differs depending on the fuel form. The least impact is observed for CORAIL-PNA, where the use of enriched uranium reduces the sensitivity to the changing isotopic composition of the recycled materials by allowing lower plutonium enrichment. The reduction in benefit as measured by the increase in repository drift loading is slightly less than $30 \%$. The greatest impact is observed with IMF, since IMF depends entirely on the fissile content of the recovered materials, which is mostly plutonium, and more fissile is needed as the composition and 
isotopic distribution changes with age. In this case, the reduction in drift loading benefit is over $75 \%$. The effect on MOX is between these two, with a reduction in the allowable drift loading increase of about $50 \%$, due to the use of a uranium matrix that provides additional fissile material during irradiation. The overall effect is that for a single recycle step using older fuel, the use of IMF is comparable to using CORAIL-PNA, with the benefit of using MOX becoming minimal.

Table III.3 provides normalized discharge masses for actinides from spent $\mathrm{UO}_{2}$, and firstrecycle MOX and IMF assemblies. The data were normalized to the net energy produced (kg/TWd), since this reflects the amount of each nuclide disposed in the repository while taking into account the displacement of directly-disposed $\mathrm{UO}_{2}$ in the recycle scenarios. For the discharged MOX fuel, the normalized Am-241 chain mass is not affected by the longer cooling time; similar behavior was also observed for the CORAIL case. The higher concentration of Am-241 in the repository waste is balanced by a reduction of the normalized Pu-241 mass. There are, however, slight increases in the normalized discharge masses of $\mathrm{Pu}-238, \mathrm{Pu}-239$, and $\mathrm{Pu}-240$ when the cooling time is increased, primarily due to the higher TRU loading in the fabricated fuel.

After a single recycle in IMF, the normalized Am-241 chain mass discharged to the repository is $65 \%$ higher when reprocessing/recycling is delayed from 5 to 20 years after $\mathrm{UO}_{2}$ discharge, and the Pu-238 mass sent to the repository is $50 \%$ higher. Likewise, the normalized $\mathrm{Pu}-239$ and $\mathrm{Pu}-240$ masses are $350 \%$ and $60 \%$ greater, respectively. The penalty associated with delaying TRU recycling in IMF is largely due to the increased Am-241 chain mass disposed in repository waste. About half of this increase is from an increase of the normalized Am-241 mass at discharge, due to a higher TRU loading in the fabricated assembly and a higher Am-241 fraction in the TRU. The remainder is due to an increase in the discharged Pu-241 mass for the longer-cooled IMF case. Relative to the 5-year cooled case, the normalized Pu-241 destruction rate in the 20-year cooled case is reduced by roughly $50 \%$ over the irradiation history of the IMF assembly, resulting in a higher discharge mass of Pu-241 in the repository waste. A more detailed discussion of the impact of delaying spent fuel reprocessing and recycling on the repository benefit can be found in Ref. 2 .

\section{III.3. Disposal of Process Waste with Actinides Removed (Continuous Recycling)}

Given the limited drift loading benefits that are possible with options using the direct disposal of spent fuel and with limited LWR recycling, processing of the spent fuel and using continuous recycling is the next logical step, as discussed in earlier work.[1,8,9] As in the previous section, the separations have been generalized to consider separation of all of the transuranic (TRU) elements, although curium is only a minor contributor to the decay heat, and the contribution from neptunium is negligible. In this study, the placement time, ventilation time, and drift spacing are all considered as variable, so that it is possible to reexamine some of the conclusions reached in the earlier work to determine if the same benefits of additional processing apply. Note that since all of the transuranic elements are being separated and recycled, the time of processing to separate the elements is less important. In particular, the question of the need to also separate cesium 
Table III.3. Discharged ${ }^{\mathrm{a}} \mathrm{UO}_{2}$, First Recycle MOX, and First Recycle IMF Nuclide Masses (kg/TWd) .

\begin{tabular}{|c|c|c|c|c|c|}
\hline \multirow[b]{2}{*}{ Nuclide } & \multirow[b]{2}{*}{$\begin{array}{c}\mathrm{UO}_{2} \\
4.3 \text { wt. \% } \\
\mathrm{U}-235\end{array}$} & \multicolumn{2}{|c|}{ First Recycle MOX } & \multicolumn{2}{|c|}{ First Recycle IMF } \\
\hline & & \begin{tabular}{|c|}
17.4 wt. $\%$ \\
TRU/HM (5- \\
Year Cooled \\
TRU) \\
\end{tabular} & $\begin{array}{c}27.7 \text { wt. } \% \\
\text { TRU/HM } \\
\text { (20-Year } \\
\text { Cooled } \\
\text { TRU) } \\
\end{array}$ & $\begin{array}{c}21.3 \text { wt. } \% \\
\text { TRU in } \mathrm{ZrO}_{2} \\
\text { matrix (5- } \\
\text { Year Cooled } \\
\text { TRU) }\end{array}$ & $\begin{array}{c}30.0 \text { wt. \% TRU } \\
\text { in } \mathrm{ZrO}_{2} \text { matrix } \\
\text { (20-Year } \\
\text { Cooled TRU) }\end{array}$ \\
\hline Am241 & 9 & 12 & 18 & 5 & 11 \\
\hline Am242m & 0 & 0 & 0 & 0 & 0 \\
\hline Am243 & 4 & 5 & 4 & 6 & 5 \\
\hline Americium & 12 & 17 & 23 & 11 & 16 \\
\hline Curium & 1.5 & 2.7 & 2.0 & 5.5 & 4.3 \\
\hline Neptunium & 12 & 8 & 8 & 3 & 5 \\
\hline Pu238 & 6 & 13 & 14 & 12 & 18 \\
\hline Pu239 & 121 & 77 & 86 & 7 & 25 \\
\hline $\mathrm{Pu} 240$ & 57 & 51 & 54 & 25 & 40 \\
\hline Pu241 & 27 & 18 & 13 & 11 & 16 \\
\hline Pu242 & 17 & 17 & 16 & 22 & 18 \\
\hline Plutonium & 228 & 175 & 183 & 78 & 117 \\
\hline U235 & 151 & 6 & 4 & 0 & 0 \\
\hline U238 & 18,059 & 1,066 & 602 & 0 & 0 \\
\hline Uranium & 18,325 & 1,080 & 610 & 1 & 1 \\
\hline Am-241 Chain & 36 & 31 & 31 & 16 & 27 \\
\hline TRU & 255 & 203 & 216 & 97 & 143 \\
\hline
\end{tabular}

${ }^{\mathrm{a}}$ After five years post-irradiation cooling.

${ }^{\mathrm{b}}$ Normalized to net energy extracted from TRU before disposal. Net burnup is: $\mathrm{UO}_{2}, 51 \mathrm{GWd} / \mathrm{MT}$; MOX, 739 GWd/MT; MOX(20-yr cooled), 1148 GWd/MT; IMF, 4507 GWd/MT; IMF(20-yr cooled), 4331 GWd/MT.

and strontium is important because some processing strategies may not be able to perform this step as easily as other strategies.

\section{III.3.a Reference Case: Disposal 25 years After Discharge}

To study the effects of delaying placement, extending ventilation, and altering drift spacing, the spent PWR fuel was assumed to be processed, resulting in the removal of 99.9\% of the TRU from the process waste. The TRU contain the plutonium and americium, the main heat producing elements contributing to constraining repository drift loading. Uranium is usually also removed and sent to separate storage, but uranium adds only a negligible contribution to the decay heat, and has no effect on the repository temperatures. The transient behavior of the repository in response to emplacing the resulting process waste, containing all fission products and $0.1 \%$ of the TRU, is shown in Figure III.5. It is observed that the transient behavior of the repository for the placement of the process waste is different than for the direct disposal of spent PWR fuel 


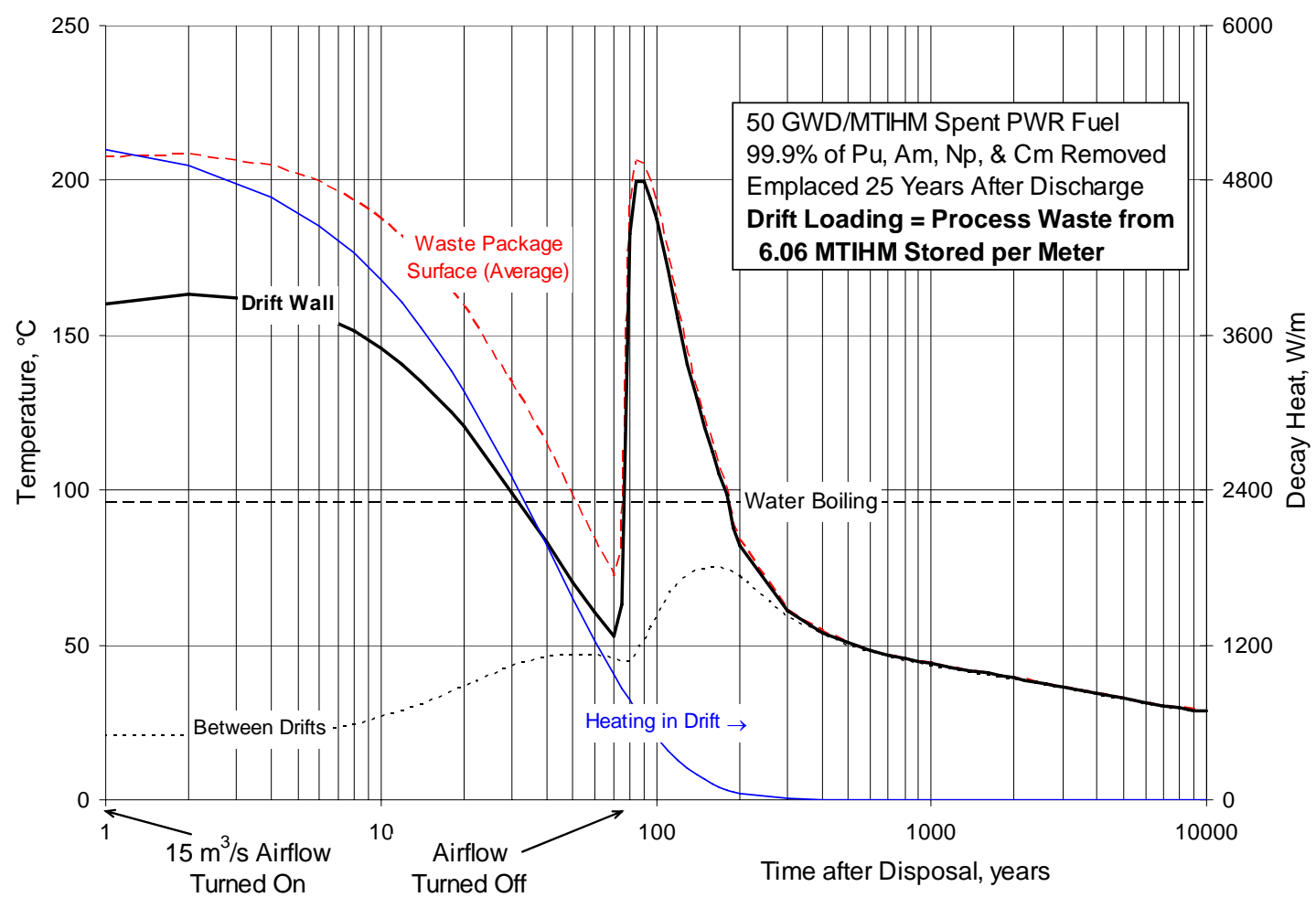

Figure III.5. Transient thermal behavior of a repository at Yucca Mountain for a drift in the central region of the repository; process waste, 99.9\% TRU removed, drift loading increased to $6.06 \mathrm{MTIHM} / \mathrm{m}$ (waste from processing).

as shown in Figure III.1. In this case, the repository drift loading is constrained by the peak temperature reached in the rock wall of the drift shortly after closure of the repository, at about 85 years after placement. It was assumed that the process waste was emplaced in the repository 25 years after the spent PWR fuel was discharged from the reactor, the same as for the reference case with direct disposal of the spent fuel. As shown in Fig. III.5, the maximum drift loading is now 6.06 MTIHM/m (or more precisely, the drift loading of process waste from processing 6.06 MTIHM of spent fuel is being stored per meter of drift). This corresponds to an increase in drift loading by a factor of $(6.06 / 1.15)=5.27$ relative to the direct disposal of spent PWR fuel.

This result indicates that the change in the composition of the material emplaced in the repository has a substantial effect on repository behavior, as would be expected. The long-lived decay-heat-producing TRU elements have been almost entirely removed, leaving short-lived isotopes to dominate. With the drift loading now constrained by temperatures that peak immediately after the end of the ventilation period, it is useful to examine the effects of delaying placement, extending ventilation, and taking advantage of the lower temperatures midway between adjacent drifts to increase the repository drift loading (or area loading in the case of also adjusting drift spacing). The effects of delaying placement and extending ventilation are examined separately, and then in combination. There is also the potential for moving the repository drifts closer together, since the peak temperature midway between adjacent drifts is only $75^{\circ} \mathrm{C}$, but the effect of this change will be discussed after consideration of the other two modifications, since it is 
the only change that would require redesign of the repository rather than just a change in operating conditions.

\section{III.3.b. Effect of Delaying Placement of Process Waste with 99.9\% TRU Removal}

The effect of delaying placement of the process waste has been evaluated for delay times of 50 years to 150 years, up from the reference value of 25 years. The duration of the ventilation period was maintained at 75 years after placement. In each case, when the drift loading is increased to the maximum allowable, the transient behavior of the repository is virtually identical to that observed at 25 years. However, the additional delay time before placement allows more of the short-lived isotopes to decay and not contribute to the decay heat. The effect of delaying placement is summarized in Table III.4.

Table III.4. Maximum drift loading for delaying placement of process waste with $99.9 \%$ TRU removal.

\begin{tabular}{|c|l|l|l|l|}
\hline $\begin{array}{l}\text { Delay } \\
\text { Time }\end{array}$ & $\begin{array}{l}\text { Maximum Drift } \\
\text { Loading } \\
\left(\mathrm{MTIHM} / \mathrm{m}^{1}\right)\end{array}$ & $\begin{array}{l}\text { Relative Drift } \\
\text { Loading } \\
\text { Increase }^{2}\end{array}$ & $\begin{array}{l}\text { Drift Loading } \\
\text { Increase Over } \\
\text { Base Case }^{3}\end{array}$ & $\begin{array}{l}\text { Limiting Temperature } \\
\left.\text { (Time }^{4}\right)\end{array}$ \\
\hline 25 years & 6.06 & 5.27 & 5.27 & Drift wall (85 years) \\
\hline 50 years & 10.7 & 8.70 & 9.30 & Drift wall (85 years) \\
\hline 75 years & 19.3 & 15.2 & 16.8 & Drift wall (85 years) \\
\hline 100 years & 34.0 & 26.0 & 29.6 & Drift wall (85 years) \\
\hline 125 years & 59.0 & 43.1 & 51.3 & Drift wall (85 years) \\
\hline 150 years & 100.0 & 70.4 & 87.0 & Drift wall (85 years) \\
\hline
\end{tabular}

${ }^{1}$ Drift loading is for the waste from processing this amount of material being stored per meter.

${ }^{2}$ Relative drift loading increase comparing the maximum drift loading for the process waste with $99.9 \%$ TRU removal to the maximum drift loading for spent PWR fuel with the same delay time prior to placement.

${ }^{3}$ Relative drift loading increase comparing the maximum drift loading for the process waste with $99.9 \%$ TRU removal to the base case maximum drift loading for spent PWR fuel with a 25 year delay time prior to placement (Figure III.1).

${ }^{4}$ Time listed is after placement; 85 years is only 10 years after repository closure.

In contrast to the effects observed with the delay in placement of the spent PWR fuel, delaying the placement of the process waste with 99.9\% TRU removal has a substantial benefit for drift loading. This is a result of the repository loading being limited by the heat load at the time of repository closure, where the dominant decay heat contributors are cesium and strontium, along with their decay products barium and yttrium. The halflives of cesium and strontium are 30 and 29 years, respectively, so that increases in delay time on the same order as the half-lives would be expected to have a significant impact. If the delay time is increased sufficiently, estimated to be about 175 years, the drift loading benefit approaches the factor of 100 that is obtained if the cesium and strontium are removed from the process waste.[7]

Since the limiting temperature is in the immediate post-closure period, there is the opportunity to use extended ventilation to further increase the drift loading, instead of by 
increasing the delay time. There is also the opportunity to move the drifts closer together, as will be discussed below.

\section{III.3.c. Effect of Extending Ventilation for Process Waste with 99.9\% TRU Removal}

The effects of extending the ventilation period have also been evaluated, using the same reference air flow rate in the drift. The results for increasing the ventilation period to 100 years from 75 years are shown in Figure III.6 using the reference placement time of 25 years. In the analyses, the drift loading has been increased to $7.50 \mathrm{MTIHM} / \mathrm{m}$ (waste from processing this quantity of spent fuel being stored per meter). As shown in the figure, the peak drift wall temperature after the end of the ventilation period is only about $150{ }^{\circ} \mathrm{C}$, and no longer limits the drift loading. The peak temperature limiting drift loading occurs within a year or two after waste package placement, where the drift wall temperature is $200{ }^{\circ} \mathrm{C}$. Therefore, due to the change in the repository behavior, the benefits of extending the ventilation period are limited by the inability to remove sufficient decay heat at the time of placement. Ventilation periods much longer than 75 years provide only a small benefit unless the placement of the waste is also delayed.

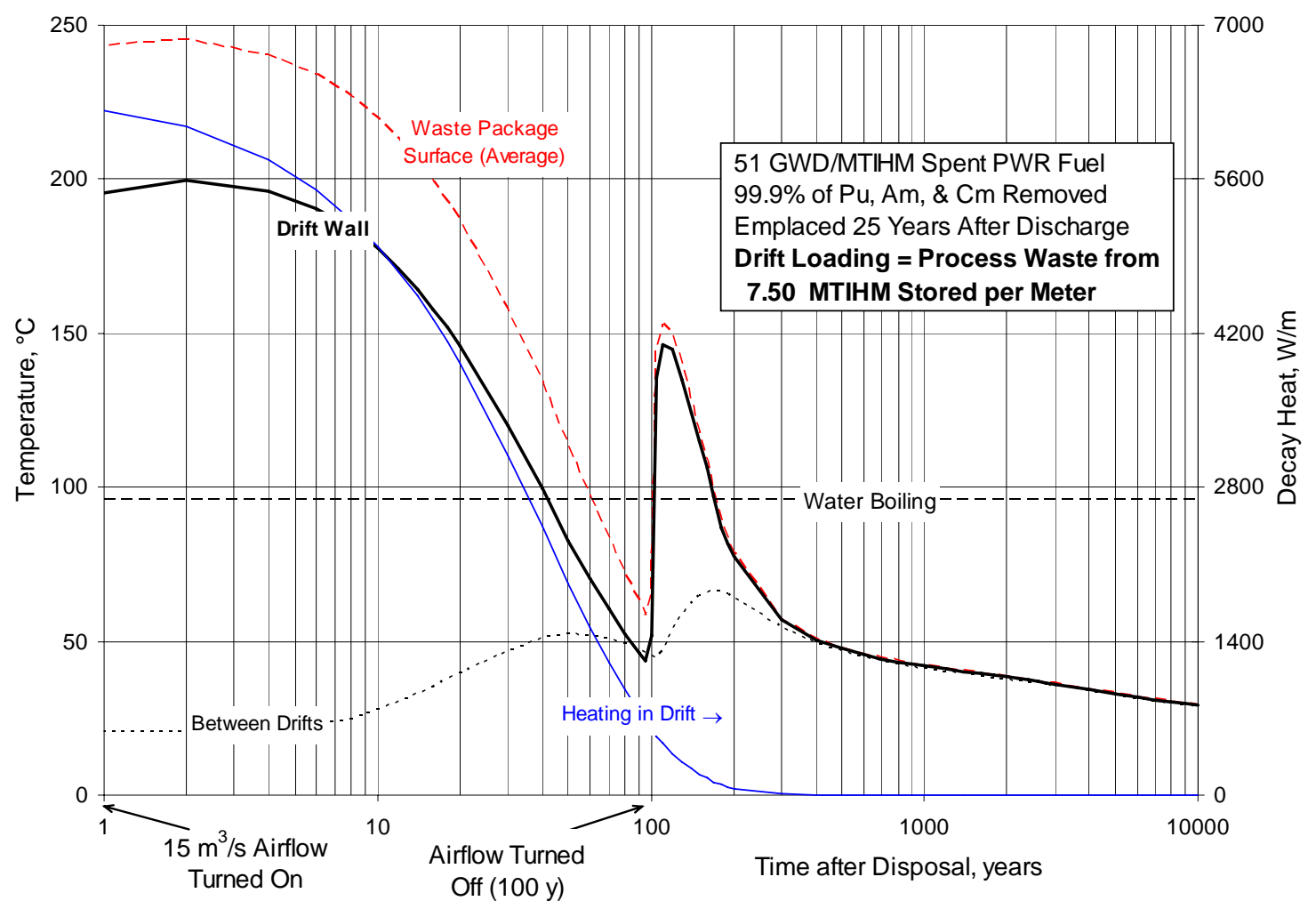

Figure III.6. Transient thermal behavior of a repository at Yucca Mountain for a drift in the central region of the repository; process waste, 99.9\% TRU removed, ventilation period increased to 100 years, drift loading increased to $7.50 \mathrm{MTIHM} / \mathrm{m}$ (waste from processing). 


\section{III.3.d. Effect of Delaying Placement and Extending Ventilation}

If the approaches of delaying placement and extending ventilation are combined, as suggested above, this could provide the opportunity for further increases in drift loading over what is achievable by either method alone. As an example, the case where placement is delayed to 50 years and ventilation is extended to 100 years was analyzed. The repository behavior is shown in Figure III.7.

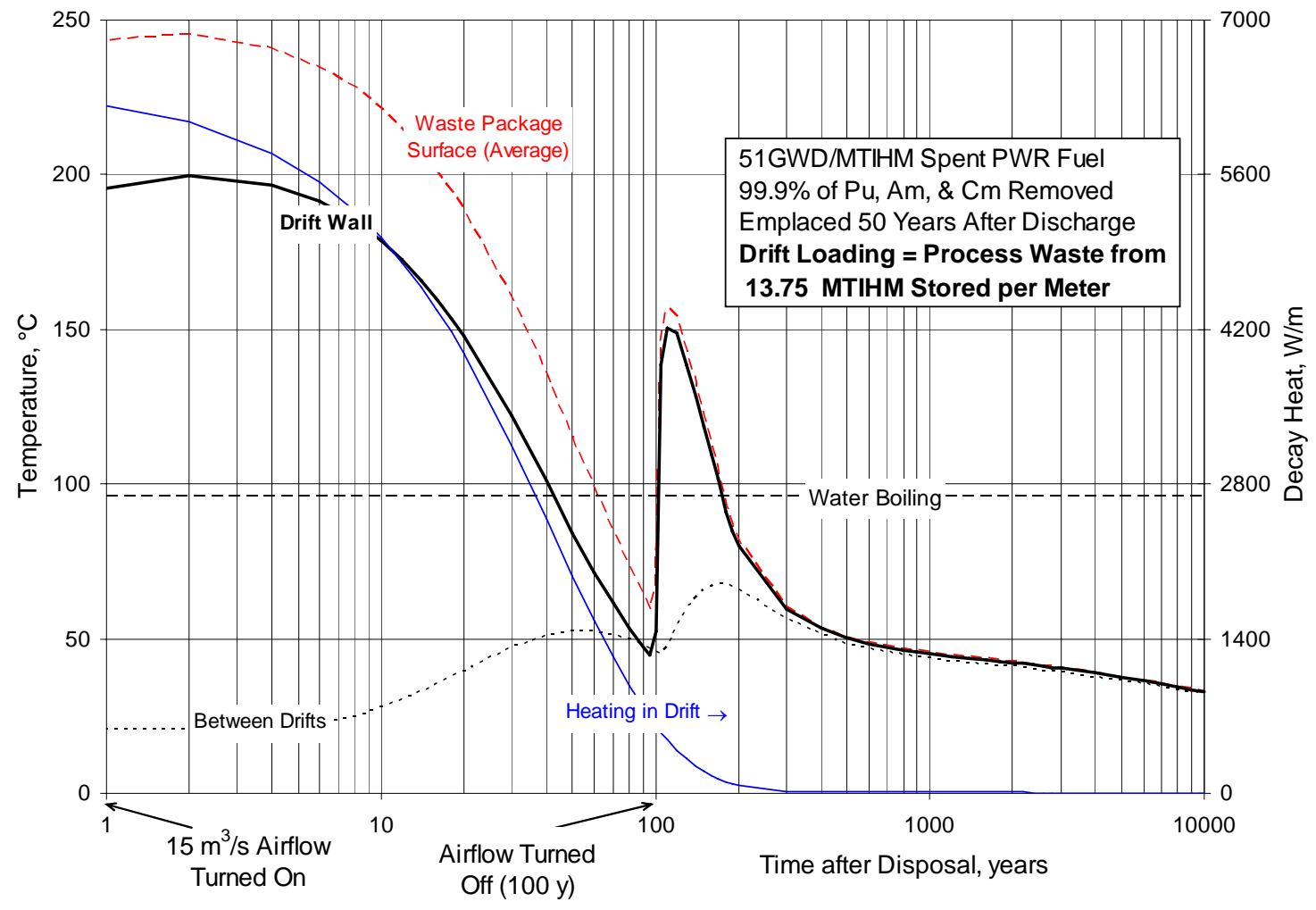

Figure III.7. Transient thermal behavior of a repository at Yucca Mountain for a drift in the central region of the repository; process waste placed at 50 years after discharge, 99.9\% transuranics removed, ventilation period increased to 100 years, drift loading increased to $13.75 \mathrm{MTIHM} / \mathrm{m}$ (waste from processing).

As shown in Fig. III.7, the limiting temperature is the peak temperature achieved immediately after placement, as in Fig. III.6, but the drift loading has been increased, with the process waste from 13.75 MTIHM being stored per meter of drift, up from 7.50 $\mathrm{MTIHM} / \mathrm{m}$ and a factor of almost 12 increase from the reference case for direct disposal of spent PWR fuel 25 years after discharge. This corresponds to the reduction in the waste decay heat as a result of waiting an additional 25 years before placement, which caused the decay heat at the time of placement to drop by about the same ratio. It should be noted that the lower peak temperature immediately after the repository is closed indicates that the ventilation period is longer than necessary. It is estimated that the drift loading benefit would be achieved if the ventilation period were extended from 75 years to about 85-90 years rather than 100 . 
Based on this result, it could be expected that the effect of additional delay time and extended ventilation time can be estimated from the results already available for most cases, since the drift loading benefit is directly proportional to the drop in decay heat at the time of placement with a 100 year ventilation period. This would remain true until the nature of the repository response changed to being limited by the temperature midway between adjacent drifts, as noted above.

\section{III.3.e. Effect of Altering Drift Spacing for Process Waste with $99.9 \%$ TRU Removal}

The next effect that was evaluated was altering the drift spacing to take advantage of the lower peak temperatures midway between adjacent drifts that occurs with processing of the spent PWR fuel to remove the TRU. (It was shown above that since the drift loading for the direct disposal of spent PWR fuel is limited by the peak temperature midway between adjacent drifts, there is no opportunity to move drifts closer in that case.)

Beginning with the case for disposal of the process waste with 99.9\% TRU removal, emplaced 25 years after discharge from the reactor, and with a ventilation period of 75 years, it was determined that it was possible to reduce the drift spacing to about 60 meters (from 81 meters), while only reducing the drift loading from $6.06 \mathrm{MTIHM} / \mathrm{m}$ to 5.90 $\mathrm{MTIHM} / \mathrm{m}$. Since the drift spacing is being changed, it is more appropriate to consider an area loading increase rather than just a drift loading increase. (For constant drift spacing, the area loading increase and the drift loading increase are the same.) In this case, the area loading increase is a factor of 6.93, up from 5.27 as listed in Table III.4.

Table III.5. Maximum drift loading for reducing drift spacing to $27 \mathrm{~m}$, extending ventilation, and delaying placement of process waste with 99.9\% TRU removal.

\begin{tabular}{|l|l|l|l|l|l|}
\hline $\begin{array}{l}\text { Delay } \\
\text { Time }\end{array}$ & $\begin{array}{l}\text { Ventilation } \\
\text { Time }\end{array}$ & $\begin{array}{l}\text { Maximum } \\
\text { Drift } \\
\text { Loading } \\
\left(\mathrm{MTIHM} / \mathrm{m}^{1}\right)\end{array}$ & $\begin{array}{l}\text { Relative } \\
\text { Area } \\
\text { Loading }^{2} \\
\text { Increase }^{2}\end{array}$ & $\begin{array}{l}\text { Area Loading } \\
\text { Increase Over }\end{array}$ & $\begin{array}{l}\text { Limiting Temperature } \\
\text { Base Case }^{3}\end{array}$ \\
\hline 50 years & 100 years & 8.40 & 20.5 & 21.9 & $\begin{array}{l}\text { Midway between } \\
\text { drifts (165 years) }\end{array}$ \\
\hline 50 years & 125 years & 11.60 & 28.3 & 30.3 & $\begin{array}{l}\text { Midway between } \\
\text { drifts (25 years) }\end{array}$ \\
\hline 75 years & 100 years & 14.00 & 15.20 & 36.5 & $\begin{array}{l}\text { Midway between } \\
\text { drifts (165 years) }\end{array}$ \\
\hline 75 years & 125 years & 20.0 & 26.0 & 52.2 & $\begin{array}{l}\text { Midway between } \\
\text { drifts (25 years) }\end{array}$ \\
\hline
\end{tabular}

${ }^{1}$ Drift loading is for the waste from processing this amount of material being stored per meter.

${ }^{2}$ Relative area loading increase comparing the maximum area loading for the process waste with $99.9 \%$ TRU removal to the maximum area loading for spent PWR fuel with the same delay time prior to placement.

${ }^{3}$ Relative area loading increase comparing the maximum area loading for the process waste with $99.9 \%$ TRU removal to the base case maximum area loading for spent PWR fuel with a 25 year delay time prior to placement.

${ }^{4}$ Time listed is after placement. 
Combining alteration of the drift spacing with delaying placement and extending ventilation results in larger benefits, as shown in the Table III.5. It was decided to use a minimum drift spacing of $27 \mathrm{~m}$ in this study, about the drift spacing considered in a previous design for a repository at Yucca Mountain. Estimates of the maximum area loading were obtained by using the maximum drift loading at an $81 \mathrm{~m}$ drift spacing, controlled by the peak drift wall temperature, and then reducing the drift spacing while maintaining this maximum drift loading until the peak temperature midway between drifts also became limiting. An alternate approach is to use a $27 \mathrm{~m}$ drift spacing (an estimate of the smallest practical drift spacing) with its maximum allowable drift loading for this drift spacing, constrained by the peak temperature midway between adjacent drifts. As a consequence, the maximum drift loading for a $27 \mathrm{~m}$ drift spacing is lower than the maximum allowable drift loading with an $81 \mathrm{~m}$ drift spacing. Comparison of these two approaches showed that the maximum area loading is approximately the same, so either approach can be used to estimate the increase in maximum area loading.

\section{III.4. Conclusions}

This study has evaluated the effects delaying reprocessing on the maximum drift loading of spent LWR-recycle fuel and associated process wastes. Also considered was the effect of delaying placement, extending ventilation, and altering drift spacing on the maximum drift and area loading for the direct disposal of spent PWR fuel and for the waste from reprocessing spent PWR fuel in a continuous recycling approach. An important goal of the study was to determine if the processing strategies recommended in earlier work would be altered by considering these design and operational changes to a repository at Yucca Mountain.

\section{III.4.a. Effect of Delaying Spent Fuel Reprocessing With Limited Recycling of Transuranics}

Since the repository drift loading for direct disposal of spent PWR fuel is controlled by the decay heat from americium (Am-241) arising from the decay of $\mathrm{Pu}-241$ in the stored spent fuel after irradiation, the analyses reported in Ref. 1 were performed for processing all spent fuel at 5 years after discharge to minimize the decay of Pu-241 and thus maximize the benefit to the repository. The benefit to the repository is also closely related to the total amount of Pu-241 (and Am-241) in the discharged fuel when the spent fuel is directly disposed in the repository. To quantify the sensitivity of the repository drift loading increase to the age of the spent fuel, analyses were conducted for one recycle of transuranics in an LWR using spent fuel that had been stored for 20 years.

As listed in Table III.5, the combination of delaying placement, extending ventilation, and moving the drifts closer together results in fairly large increases in area loading for the repository. For the case with 50 years delay in placement, and 100 years ventilation, keeping the drift spacing at $81 \mathrm{~m}$ provided a maximum loading increase of a factor of 12.0, while moving the drifts closer provides for a maximum loading increase of about 22. Further delay in placement, combined with extending ventilation, provides greater increases in loading. However, there is no benefit in extending ventilation beyond 125 
years in these cases, since the limiting temperature is occurring during the ventilation period, at about 25 years after placement.

Increasing the cooling time before reprocessing reduces the repository loading benefit due to a single recycle of plutonium, americium, and neptunium from 1.09 to 1.04 for MOX, and from 1.22 to 1.16 for CORAIL fuel. Thus, there is a small penalty on the repository loading benefit associated with recycling older transuranic material in a MOX fuel form. Relative to the reference $\mathrm{UO}_{2}$ case, the repository capacity is only $19 \%$ higher for the longer-cooled case using IMF, compared with a $79 \%$ loading benefit for a single recycle of 5-year cooled TRU. Thus, it is clear that delaying spent fuel reprocessing and recycling significantly reduces the benefits of a single IMF recycle. The penalty associated with delaying TRU recycling in IMF is largely due to the increased Am-241 chain mass disposed in repository waste. About half of this increase is due to an increase of the normalized Am-241 mass at discharge, and the remainder is due to an increase in the discharged Pu-241 mass for the longer-cooled IMF case.

\section{III.4.b. Direct Disposal of Spent PWR Fuel}

For the direct disposal of spent PWR fuel, the following observations and conclusions have been made:

1) The repository drift loading for the direct disposal of spent PWR fuel with the reference conditions (placement at 25 years after discharge, ventilation for 75 years after placement, and drift spacing of 81 meters) is constrained by the temperature limit midway between adjacent drifts

2) Delaying placement of the spent PWR fuel allows the drift loading to be increased, as shown in Table III.3, up to a factor of 1.23 for a placement delay of 150 years after discharge from the reactor. In each case, delaying the time of placement in the range of 25 to 150 years after discharge from the reactor, the drift loading is always limited by the peak temperature midway between adjacent drifts. As a result, there is no opportunity to alter the drift spacing to increase the area loading of the repository.

3) Extending the ventilation period for a given placement delay time provides nearly the same benefit as delaying placement since no temperature limits are met during the ventilation period. During the ventilation phase, most of the decay heat is removed from the repository by the ventilation, which is similar to the effect of delaying placement, i.e., less heat is transferred into the repository.

4) Combining both delaying placement and extending ventilation provides about the same benefit as if either of these changes were applied for the same time period, i.e., delaying placement for 50 years and ventilating the repository for 100 years is about the same as delaying placement for 75 years and ventilating the repository for 75 years.

As a consequence, as long as direct disposal of spent PWR fuel is being planned, the potential gain in repository drift loading from either delaying placement or extending ventilation would be considered as relatively small, at most a factor of 1.23 for waiting 150 years. 


\section{III.4.c. Disposal of Process Waste with 99.9\% Removal of TRU (Continuous Recycling)}

Prior work has shown that the first processing step that needs to be performed on spent PWR fuel to provide more substantial increases in drift loading is the removal of americium and plutonium.[1,7,8,9,10] In this study, the more general case of removing all of the TRU elements (americium, plutonium, neptunium and curium), is being considered, although neptunium removal has no effect on the decay heat and curium removal is only important if other elements have been removed first. For spent PWR fuel that is processed prior to disposal to remove 99.9\% of the TRU, the following observations and conclusions can be made:

1) For the reference repository design and operating conditions, the drift loading can be increased from 1.15 MTIHM/m for direct disposal of spent PWR fuel to the waste from processing 6.06 MTIHM being stored per meter, a factor of 5.27. Drift loading is limited by the peak drift wall temperature immediately after repository closure, so that moving the drifts closer together is possible within the applicable temperature limits. Reducing the drift spacing increases the factor for the area loading of the repository to 6.93.

2) Delaying placement of the process waste provides substantial increases in repository drift loading, as shown in Table III.4, because the repository drift loading is now determined by the decay heat from relatively short-lived isotopes with half-lives on the order of 30 years. The benefit is approximately proportional to the decay of these elements, providing a drift loading benefit factor from 9.3 with 50 years delay in placement to 87.0 with 150 years delay. In addition, since the drift loading is not limited by the peak temperature midway between drifts, it is possible to move the drifts closer together. In general, the longer the delay in placement, the less the drifts can be moved.

3) Extending the ventilation period is of limited benefit, even though it can reduce the peak drift wall temperature immediately after closure, because the peak drift wall temperature immediately after placement is high, over $150{ }^{\circ} \mathrm{C}$, and only a small increase in drift loading is needed for these temperatures to reach the limit of $200{ }^{\circ} \mathrm{C}$. For the reference conditions of 25 years delay in placement and 81 meter drift spacing, the maximum drift loading can be increased from 6.06 $\mathrm{MTIHM} / \mathrm{m}$ up to $7.50 \mathrm{MTIHM} / \mathrm{m}$.

4) Using all effects in combination results in alternative approaches to achieving large gains in the area loading of a repository at Yucca Mountain, as shown in Table III.5. However, whether one uses such a combination, or merely chooses to delay placement as shown in Table III.4, the overall benefits are about the same given a specified time period where the decay heat is not transferred into the repository.

\section{III.4.d. The Need for the Removal of Cesium and Strontium from the Process Waste}

When the reference operating conditions of the repository are used (placement 25 years after discharge from the reactor, ventilation for 75 years, and 81 meter drift spacing), there is a large benefit from subsequently removing the cesium and strontium from the process waste after the TRU elements have been separated.[7] Increases in drift loading of about 100 are possible with this method. In this study, it has been shown that by 
delaying placement, extending ventilation, and altering drift spacing, similar increases in drift loading are possible, with the following observations and conclusions:

1) With the removal of $99.9 \%$ of the TRU content, the decay heat and the repository drift loading are determined by the decay heat from cesium and strontium, and their decay products barium and yttrium. The short half-lives of these elements, about 30 years, make it possible to reduce the effect of their decay heat by measures which are effective over similar time periods. Delaying placement by one half-life is essentially equivalent to removing half the content of these elements from the process waste. Further delay is equivalent to removing more, so that by about 175 years, the effect of the remaining cesium and strontium is equivalent to having removed these elements during processing.

2) The decision to choose processing to remove the cesium and strontium, or to delay the placement of the process waste, increase the ventilation time, and possibly alter the drift spacing, would need to be made based on other considerations, which could include cost, timeliness, storage, etc. It is clear that substantial benefit to the drift or area loading of the repository can be achieved with either approach.

In summary, depending on the repository behavior and the resulting limiting temperature, the effects of delaying placement and extending ventilation may be either approximately equivalent, or quite different, as follows:

1. If the repository loading is limited by the temperature midway between adjacent drifts, then delaying placement or extending ventilation provide roughly the same benefit as measured by increasing the drift loading.

2. If the repository loading is limited by the temperature immediately after repository closure, then delaying placement or extending ventilation would provide roughly the same benefit only if the ventilation is sufficient to remove the decay heat at the time of placement without exceeding the drift wall temperature limit. Otherwise, the benefits of extending ventilation would be much less than for delaying placement. Drift spacing reduction is possible for further drift loading increase.

3. If the repository loading is limited by the temperature immediately after placement of the waste in the repository, then extending ventilation would provide no benefit, while delaying placement would result in a large benefit. Drift spacing reduction is possible for further drift loading increase.

As a closing note, it is not possible to overemphasize the importance of having very low process losses for the TRU, especially americium and plutonium. Use of $99.9 \%$ separation and recovery in this study is viewed as a reasonable minimum goal for processing, if substantial repository benefit is desired. Even considering a process recovery of $99 \%$ results in a ten-fold increase in the TRU inventory in the waste, reducing (or even greatly reducing) the potential benefits.[7,8,10] 


\section{PROLIFERATION RESISTANCE OF RECYCLED TRANSURNICS}

The impact of recycling plutonium, neptunium, and americium in commercial LWRs on the repository loading of spent nuclear waste has been evaluated. [1] Recycling in MOX, CORAIL (heterogeneous MOX, $\mathrm{UO}_{2}$ ), and inert-matrix fuel (IMF) assemblies was considered. The source of the recycled transuranics was spent $\mathrm{UO}_{2}$, discharged at 51 GWd/MT burnup ("reactor-grade").

Transuranic recycling in IMF provides a significant burn-down of the reactor-grade plutonium, and severely degrades the isotopic vector of the plutonium; 95\% of the Pu239 is consumed in a single pass. Because of this, it has been postulated that the transuranic material in the spent IMF assembly might have a substantially higher critical mass than that of reactor-grade plutonium, thus increasing its proliferation resistance.

\section{IV.1. Critical Mass and Radiation Sources}

Calculations have been performed with the MCNP [13] code to determine the critical mass of bare spheres fabricated from plutonium metal at a nominal density of $19.8 \mathrm{~g} / \mathrm{cm}^{3}$ ( $\alpha$-phase plutonium) with various isotopic vectors. Although several references report that an even lower critical mass can be achieved if reflecting material is placed around the sphere and/or the plutonium is compacted to a higher-than-nominal density, the purpose of this study was simply to evaluate the critical mass relative to weapons-grade material. Furthermore, the ORIGEN2 [14] code was used to calculate the decay heat and neutron and photon sources of the critical spheres. [15] Results are provided in Table IV.1.

An unreflected sphere of weapons-grade plutonium metal (WG-Pu in Table IV.1) has a critical mass of around $11 \mathrm{~kg}$. Also, the decay heat and radiation sources are relatively low compared with the less pure plutonium vectors. For reactor-grade plutonium harvested from spent $\mathrm{UO}_{2}$ five years after reactor discharge (RG-Pu), the critical mass is $30 \%$ higher due to the higher concentrations of Pu-240 and Pu-242. Also, the thermal energy generated by radioactive decay and the radiation sources are higher by about an order of magnitude. The values reported in Table IV.1 were calculated for the pure plutonium at the time of separation from the transuranics, and do not include any of the Am-241 which is produced from Pu-241 decay ( $\mathrm{t}_{1 / 2}=14.4$ years) after separation. Over a 50 year time period, the photon energy source $(\mathrm{MeV} / \mathrm{sec})$ for the reactor-grade material (assuming a fixed total mass) increases by another order of magnitude due to the buildup of Am-241. It is noted that in order to obtain the critical mass of reactor-grade plutonium, the spent fuel from 3 typical PWR assemblies must be reprocessed.

Two plutonium vectors from recycled fuel were considered here. The first was for plutonium harvested from a spent MOX assembly which had originally been fabricated from reactor-grade $\mathrm{Pu}+\mathrm{Np}+\mathrm{Am}$, irradiated to a discharge burnup of $51 \mathrm{GWd} / \mathrm{MT}$, and cooled for 5 years (MOX-Pu). Recycling the transuranics in this fuel form degrades the isotopic vector somewhat (32\% of the $\mathrm{Pu}-239$ is consumed in a single pass). Consequently, the critical mass of this plutonium is about $40 \%$ higher than that of weapons-grade material. The decay heat generated by the critical mass of MOX-Pu is higher than that of the reactor-grade plutonium by a factor of 2.5 because of the factor of three increase in $\mathrm{Pu}-238$ concentration. Likewise, the photon source is higher for this 
Table IV.1. Mass and Radioactive Properties for Bare Critical Spheres of Plutonium ${ }^{\mathrm{a}}$ Metal.

\begin{tabular}{|c|c|c|c|c|c|c|}
\hline & $\begin{array}{c}\text { Plutonium } \\
\text { Vector }^{\mathbf{b}}\end{array}$ & $\begin{array}{c}\text { Critical } \\
\text { Mass } \\
\text { (Rel. to } \\
\text { WG-Pu) }\end{array}$ & $\begin{array}{c}\text { Decay } \\
\text { Heat } \\
\text { (W) }\end{array}$ & $\begin{array}{c}\text { Neutron } \\
\text { Source } \\
\text { (n/sec) }\end{array}$ & $\begin{array}{c}\gamma \text { Source } \\
\text { (photons/sec) }\end{array}$ & $\begin{array}{c}\gamma \text { Source } \\
\text { (MeV/sec) }\end{array}$ \\
\hline WG-Pu & $\begin{array}{c}0.02 / 93.40 / \\
6.04 / 0.50 / \\
0.04\end{array}$ & 1 & 24.9 & $5.97 \mathrm{E}+05$ & $2.41 \mathrm{E}+12$ & $2.54 \mathrm{E}+10$ \\
\hline RG-Pu & $\begin{array}{c}2.63 / 53.08 / \\
25.11 / 11.82 / \\
7.36\end{array}$ & 1.3 & 255.6 & $5.96 \mathrm{E}+06$ & $4.50 \mathrm{E}+13$ & $4.56 \mathrm{E}+11$ \\
\hline $\begin{array}{l}\text { MOX- } \\
\text { Pu }\end{array}$ & $\begin{array}{c}7.13 / 43.80 / \\
28.94 / 10.52 / \\
9.61 \\
\end{array}$ & 1.4 & 664.6 & $9.35 E+06$ & $1.17 \mathrm{E}+14$ & $1.19 \mathrm{E}+12$ \\
\hline IMF-Pu & $\begin{array}{c}15.76 / 8.60 / \\
32.44 / 14.65 / \\
28.55\end{array}$ & 2.1 & 2057.0 & $2.66 \mathrm{E}+07$ & $3.64 \mathrm{E}+14$ & $3.69 \mathrm{E}+12$ \\
\hline $\begin{array}{l}\text { IMF- } \\
\text { HM }^{\mathbf{c}}\end{array}$ & $\begin{array}{c}15.76 / 8.60 / \\
32.44 / 14.65 / \\
28.55\end{array}$ & 2.2 & 5052.0 & $1.25 \mathrm{E}+10$ & $9.54 \mathrm{E}+14$ & $1.60 \mathrm{E}+13$ \\
\hline
\end{tabular}

${ }^{a}$ Except for weapons-grade, material is harvested from spent fuel assembly five years after reactor discharge. Critical mass and other properties were calculated at the time of separation.

${ }^{\mathrm{b}}$ Vector displayed as weight percents of Pu-238/Pu-239/Pu-240/Pu-241/Pu-242.

${ }^{\mathrm{c}}$ Heavy metal in spent IMF assembly consists of $0.9 \% \mathrm{U}, 3.5 \% \mathrm{~Np}, 79.0 \% \mathrm{Pu}, 11.0 \% \mathrm{Am}$, and $5.6 \% \mathrm{Cm}$.

material; as illustrated in Figure IV.1, Pu-238 is the primary contributor soon after isotope separation (nuclide contributions in this figure were evaluated $1 / 2$ year after separation), but Am-241 becomes quite important at later times. For the analysis assumptions utilized in Ref. 1, one spent MOX assembly contains 3 times the critical mass of plutonium.

For a bare sphere of plutonium harvested from a spent IMF assembly (again, reprocessing and separation occur 5 years after reactor discharge), the critical mass is 2.1 times that for s-grade plutonium. After a single recycle of the transuranics in IMF, the remaining plutonium is severely depleted in Pu-239, but other plutonium isotopes which are still present in appreciable fractions (i.e. $\mathrm{Pu}-238, \mathrm{Pu}-241$ ) have critical masses similar to that of pure Pu-239. In the analysis performed in Ref. 1, the spent IMF assembly contained $14.8 \mathrm{~kg}$ plutonium (37.8 $\mathrm{kg} \mathrm{Pu}$ in the unirradiated assembly); two such assemblies would have to be reprocessed to obtain a critical mass of plutonium.

An alternate case with a vector which included all heavy metal isotopes in the spent IMF assembly (the fission products were removed) was also evaluated. Including all the minor actinides increases the critical mass by only $5 \%$, compared with the case for pure plutonium. However, the decay heat and neutron source are higher by factors of 2.5 and 500, respectively, primarily due to the $\mathrm{Cm}-244$. Likewise, Figure IV.1 illustrates that the 


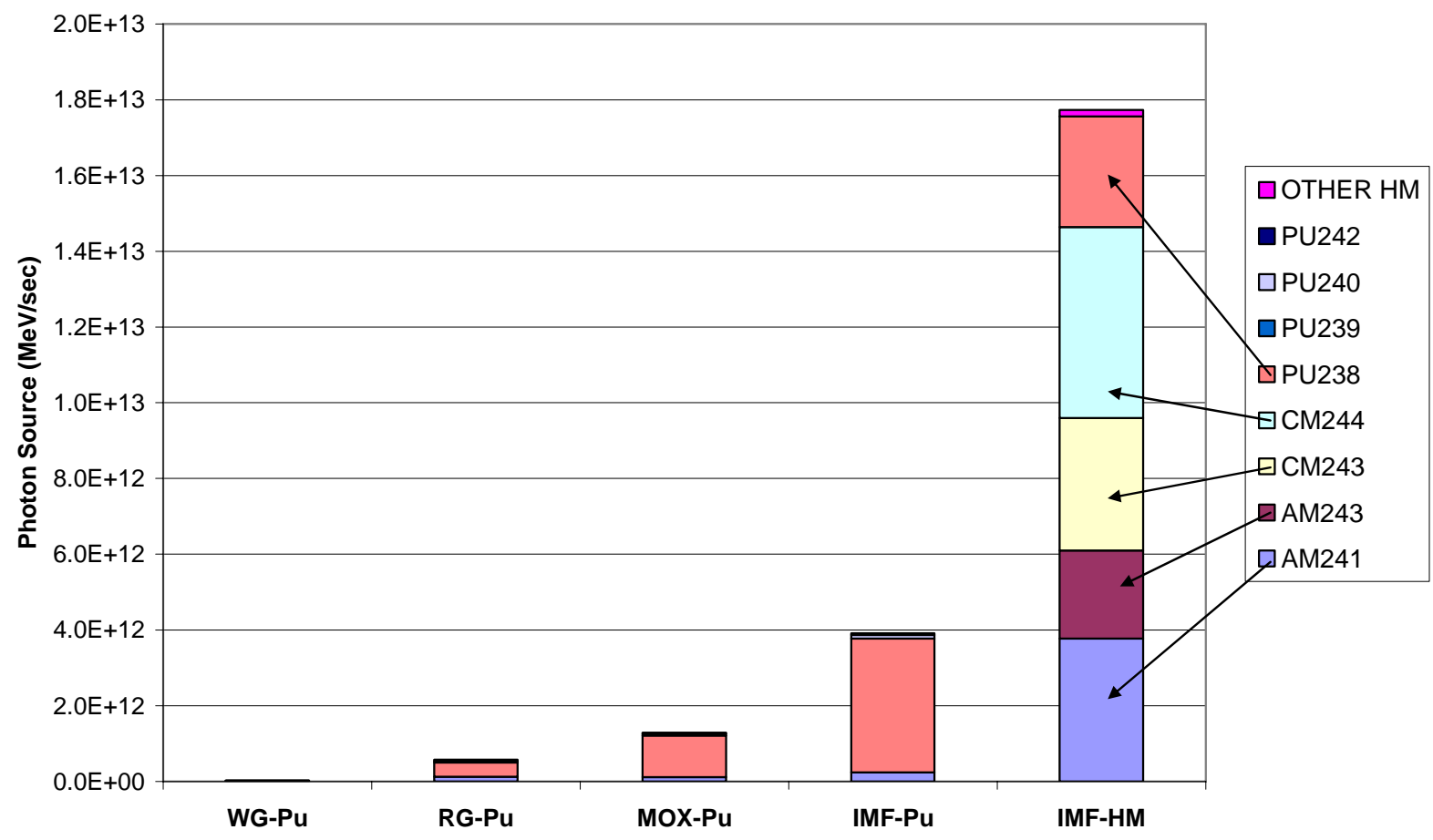

Figure IV.1. Contributors to Photon Energy Source in Critical Mass for Various

Plutonium Vectors. Values are at 0.5 years after transuranic separation.

photon energy source is higher than the IMF-Pu case by a factor of 4 because of the presence of americium and curium.

Since the IMF assembly is fabricated from transuranics only (no depleted uranium), it was considered of interest to evaluate the criticality and irradiation field of this material directly. The critical mass was calculated for the fresh ( $\mathrm{Zr}, \mathrm{TRU}) \mathrm{O}_{2}$ ( $1^{\text {st }}$ recycle), assuming the cladding was removed and the material was formed into a sphere. Because of the high volume fraction of zirconia (79\%), the density of the material is $5.6 \mathrm{~g} / \mathrm{cm}^{3}$, and the density of the heavy metal in the fuel is only $1.1 \mathrm{~g} / \mathrm{cm}^{3}$ (compared with nearly 20 $\mathrm{g} / \mathrm{cm}^{3}$ for the pure metal). Furthermore, the neutron spectrum will be softer than that of the pure metal due to the presence of oxygen and zirconium, so it is expected that the critical mass will be quite large.

Using the fabricated density of the fuel material, the critical mass for a bare sphere was calculated to be $1850 \mathrm{~kg}$. Most devises use some sort of high explosive to compact the material to lower the critical mass. No data on how much the (Zr,TRU) $\mathrm{O}_{2}$ could be compacted were available, but assuming a 50\% increase in density, the critical mass decreases to about $850 \mathrm{~kg}$. If density increases of a factor of two or more are possible, then this may be an important case to evaluate further.

\section{IV.2. Temperature Evaluation}

Although a single recycle of transuranics in IMF (or MOX) degrades the plutonium vector and increases the critical mass compared with that of weapons- or reactor-grade material, the mass increase alone does not appear to add much in terms of proliferation resistance. However, the decay heat and radiation sources are significantly elevated compared with the weapons-grade material, and this could reduce the attractiveness of 
this material. For example, it was reported in Ref. 16 that the high explosives used to compact the fissile material in an implosion-type configuraion are negatively impacted if temperatures exceed $100^{\circ} \mathrm{C}$. An internet search was employed to gather available resources; it was surprisingly easy to find data. Two explosive materials commonly mentioned as being used in weapons were HMX and TATB. All resources agreed that these explosives will become less effective (and possibly self-ignite) at elevated temperatures. Increased radiation fields can also accelerate the degradation of the explosive. The "critical temperature" at which the explosive will self-ignite is dependent on the geometry and size of the configuration. However, it is generally in the range of 150 to $250^{\circ} \mathrm{C}$. $[17,18]$

Rough thermal calculations were performed for a configuration composed of separated plutonium, assuming that the critical mass had been expanded to twice its nominal volume (to provide a sub-critical arrangement before firing) and a $10 \mathrm{~cm}$ thickness of explosive surrounded the plutonium zone (as in Ref. 16); the problem and equations are illustrated in Figure IV.2. Table IV.2 provides calculated temperatures of the core and explosive for the plutonium vectors considered here. Two different values for $\kappa_{\mathrm{HE}}$ were utilized, based on data found for $\operatorname{HMX}\left(0.4 \mathrm{~W} / \mathrm{m}^{\circ} \mathrm{C}\right)$ and TATB $(0.8$ $\mathrm{W} / \mathrm{m}^{\circ} \mathrm{C}$ ). As the thermal conductivity of the material surrounding the core decreases, the temperatures will increase due to the greater thermal insulation. The coefficient of heat transfer (h) from the surface of the explosive to the ambient air (assumed to be at $20^{\circ} \mathrm{C}$ ) was found in a textbook and is an approximate value for natural convection in air from a spherical object $30 \mathrm{~cm}$ in diameter. Although h was not calculated precisely for each case, the calculated temperatures were relatively insensitive to this value.

The average temperature of the high explosive in a configuration with weapons-grade plutonium is well below the $100^{\circ} \mathrm{C}$ limit quoted in Ref. 16. However, even the reactorgrade plutonium yields temperatures for the high explosive which appear to be

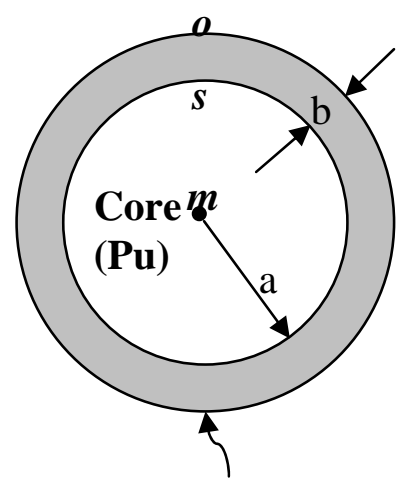

$$
\begin{aligned}
& T_{m}-T_{s}=\frac{Q a}{2 \kappa_{\text {core }} A_{a}}, T_{s}-T_{o}=\frac{Q b}{\kappa_{H E} A_{b}}, T_{o}-T_{\text {ambient }}=\frac{Q}{h A_{c}} \\
& T_{m}-T_{\text {ambient }}=Q \cdot\left[\frac{a}{2 \kappa_{\text {core }} A_{a}}+\frac{b}{\kappa_{H E} A_{b}}+\frac{1}{h A_{c}}\right] \\
& \overline{T_{\text {core }}}=\frac{1}{5}\left(2 T_{m}+3 T_{s}\right) \\
& \overline{T_{H E}}=T_{s}-\frac{T_{s}-T_{o}}{1-1 / \alpha}\left[1-\frac{3\left(\alpha^{2}-1\right)}{2\left(\alpha^{3}-1\right)}\right], \alpha=1+\frac{b}{a} \\
& A_{a}=4 \pi a^{2} \quad A_{b}=4 \pi a(a+b) \quad A_{c}=4 \pi(a+b)^{2}
\end{aligned}
$$

Figure IV.2. Thermal Heat Conduction Equations for Spherical Geometry. 
Table IV.2. Temperatures Calculated for an Implosion-Type Configuration. (For a critical mass surrounded by a $10 \mathrm{~cm}$ thickness of high explosive and an ambient air temperature of $20^{\circ} \mathrm{C}$.)

\begin{tabular}{|c|c|c|c|c|c|c|c|c|}
\hline & $\begin{array}{c}\kappa_{\text {core }} \\
\left(W / m^{0} \mathrm{C}\right)\end{array}$ & $\begin{array}{c}\kappa_{\mathrm{HE}} \\
\left(\mathrm{W} / \mathbf{m}^{\mathbf{0}} \mathbf{C}\right)\end{array}$ & $\begin{array}{c}\mathbf{h} \\
\left(\mathrm{W} / \mathbf{m}^{2}{ }^{0} \mathrm{C}\right)\end{array}$ & $\begin{array}{c}\text { Decay } \\
\text { Heat } \\
\text { (W) }\end{array}$ & $\begin{array}{c}\mathrm{T}_{\mathrm{m}} \\
\left({ }^{\circ} \mathrm{C}\right)\end{array}$ & $\begin{array}{c}\mathrm{T}_{\mathrm{s}} \\
\left({ }^{\circ} \mathrm{C}\right)\end{array}$ & $\begin{array}{l}\overline{T_{\text {core }}} \\
\left({ }^{\circ} \mathrm{C}\right)\end{array}$ & $\begin{array}{l}\overline{\mathrm{T}_{\mathrm{HE}}} \\
\left({ }^{\circ} \mathrm{C}\right)\end{array}$ \\
\hline WG-Pu & \multirow{5}{*}{$10,-1$} & \multirow{5}{*}{0.4} & \multirow{5}{*}{6} & 24.9 & 82.7 & 80.1 & 81.2 & 41.6 \\
\hline RG-Pu & & & & 255.6 & 590.9 & 566.6 & 576.3 & 225.9 \\
\hline MOX-Pu & & & & 664.6 & 1457.8 & 1396.3 & 1420.9 & 544.7 \\
\hline IMF-Pu & & & & 2057.0 & 3796.0 & 3628.1 & 3695.3 & 1478.8 \\
\hline IMF-HM & & & & 5052.0 & 9108.9 & 8703.0 & 8865.3 & 3554.7 \\
\hline WG-Pu & \multirow{5}{*}{6} & \multirow{5}{*}{0.8} & \multirow{5}{*}{6} & 24.9 & 58.8 & 56.2 & 57.3 & 37.0 \\
\hline RG-Pu & & & & 255.6 & 376.4 & 352.1 & 361.8 & 181.7 \\
\hline MOX-Pu & & & & 664.6 & 919.4 & 857.9 & 882.5 & 432.1 \\
\hline IMF-Pu & & & & 2057.0 & 2407.0 & 2239.2 & 2306.3 & 1164.6 \\
\hline IMF-HM & & & & 5052.0 & 5773.0 & 5367.0 & 5529.4 & 2792.9 \\
\hline
\end{tabular}

quite high compared to the weapons-grade material. For the cases with plutonium or heavy metal separated from recycled MOX or IMF, the temperature of the plutonium itself is above its melting temperature $\left(\mathrm{T}_{\text {melt }} \sim 640^{\circ} \mathrm{C}\right)$. Of course, methods could be devised to cool the transuranic material (the idea of a "thermal bridge" of aluminum is suggested in Ref. 16), but the point is clearly made that the elevated decay heat complicates the utilization of such configurations.

Table IV.3 provides temperatures of critical spheres of the various grades of plutonium considered in this study, surrounded only by air at room temperature. In these calculations, the nuclear material was assumed to be cooled only by natural convection. Without the surrounding high explosive, this provides a measure of the material state during transport. As in the previous calculations, the thermal conductivity of the plutonium metal was assumed to be $6 \mathrm{~W} / \mathrm{m}^{\circ} \mathrm{C}$, and the heat transfer coefficient for natural convection was fixed at $6 \mathrm{~W} / \mathrm{m}^{2}{ }^{\circ} \mathrm{C}$.

The first set of results in Table IV.3 are for a critical mass of plutonium in a spherical shape, with the material volume doubled to ensure a sub-critical configuration (1/2 nominal density). This is the same as the condition of the core assumed in the temperature calculations reported in Table IV.2. Without the surrounding highexplosive, the temperature of the plutonium metal is actually higher because the outside surface area of the body (parameter $A_{c}$ in Figure IV.2) is lower, reducing the amount of heat disipated by natural convection. The melting temperature of plutonium is $\sim 640^{\circ} \mathrm{C}$, so unless the material is reconfigured to increase its surface area, or some other means of cooling is employed, critical-mass spheres of all grades of plutonium but weapons-grade would be molten.

Another set of calculations were performed with the material density decreased to $10 \%$ of its nominal density $\left(1.98 \mathrm{~g} / \mathrm{cm}^{3}\right)$. Increasing the material volume (surface area) reduces its temperature, but the IMF-Pu and IMF-HM materials are still above the melting temperature of plutonium. It should be noted however, that the thermal 
Table IV.3. Temperatures Calculated for Spherical Critical Mass of Various

Grades of Plutonium. (Ambient air temperature of $20^{\circ} \mathrm{C}$.)

\begin{tabular}{|c|c|c|c|c|c|c|c|}
\hline & $\begin{array}{c}\kappa_{\text {metal }} \\
\left(\mathrm{W} / \mathbf{m}^{0} \mathbf{C}\right)\end{array}$ & $\begin{array}{c}\mathbf{h} \\
\left(\mathrm{W} / \mathrm{m}^{2}-^{0} \mathrm{C}\right)\end{array}$ & $\begin{array}{c}\text { Volume } \\
\text { Expansion }\end{array}$ & $\begin{array}{c}\text { Decay } \\
\text { Heat } \\
\text { (W) }\end{array}$ & $\begin{array}{l}\mathbf{T}_{\mathrm{m}} \\
\left({ }^{\circ} \mathrm{C}\right)\end{array}$ & $\begin{array}{c}T_{s} \\
\left({ }^{0} \mathrm{C}\right)\end{array}$ & $\begin{array}{c}\overline{\mathrm{T}_{\text {sphere }}} \\
\left({ }^{\circ} \mathrm{C}\right)\end{array}$ \\
\hline WG-Pu & \multirow{5}{*}{6} & \multirow[t]{5}{*}{+2} & \multirow{5}{*}{$\mathrm{x} 2$} & 24.9 & 104.6 & 102.0 & 103.0 \\
\hline RG-Pu & & & & 255.6 & 740.0 & 715.7 & 725.4 \\
\hline MOX-Pu & & & & 664.6 & 1802.5 & 1740.9 & 1765.6 \\
\hline IMF-Pu & & & & 2057.0 & 4318.4 & 4150.6 & 4217.7 \\
\hline IMF-HM & & & & 5052.0 & 10263.3 & 9857.4 & 10019.7 \\
\hline WG-Pu & \multirow{5}{*}{6} & \multirow{5}{*}{6} & \multirow{5}{*}{$\mathrm{x} 10$} & 24.9 & 49.7 & 48.1 & 48.8 \\
\hline RG-Pu & & & & 255.6 & 273.2 & 258.9 & 264.6 \\
\hline MOX-Pu & & & & 664.6 & 647.1 & 611.1 & 625.5 \\
\hline IMF-Pu & & & & 2057.0 & 1537.0 & 1438.7 & 1478.0 \\
\hline IMF-HM & & & & 5052.0 & 3636.5 & 3398.6 & 3493.8 \\
\hline
\end{tabular}

conductivity and heat transfer coefficient were not adjusted to account for the change in configuration assumed in this case. Reducing the material density by $90 \%$ would certainly alter (lower) the thermal conductivity of the sphere. Additionally, the heat transfer coefficient becomes smaller with the increasing dimension of the sphere. The combination of these two effects means that the temperatures reported in Table IV.3 are likely underpredictions of the actual temperatures.

\section{IV.3. Conclusions}

One of the arguments against direct disposal of once-through $\mathrm{UO}_{2}$ fuel assemblies is that the geologic repository becomes, in essence, a plutonium "mine." Reprocessing the spent fuel and recycling the transuranics through one or more reactor fuel cycles degrades the purity of the plutonium (less fissile content) and potentially increases the proliferation resistance of the disposed waste. Recycling reactor-grade plutonium in an inert-matrix fuel form severely degrades the material, consuming nearly $95 \%$ of the Pu-239 in a single pass. It has been found that the critical mass for the recycled plutonium is higher than that of weapons-grade material, but the required mass is at most 2 times that for weaponsgrade material, and is not considered high enough to deter potential proliferators.

However, it has also been found that the thermal and radiation sources for the grades of plutonium considered here are significantly higher than those of weapons-grade material. Heat and radiation negatively impact the usefulness of the material and the material recycled in MOX or IMF may be completely unusable for this reason. For instance, the specific decay heat (Watts/kg) of reactor-grade plutonium (from spent $\mathrm{UO}_{2}$ ) is about an order of magnitude larger than that for weapons-grade material; for plutonium which has been recycled once in MOX or IMF, the specific decay heat is a factor of 2040 higher than weapons-grade. Of course, the magnitude of the properties calculated here should be evaluated more closely to determine if the recycled material is proliferation resistant. At the very least, utilizing the recycled material would complicate the diversion and utilization of this material. 


\section{FAST REACTOR RESOURCE REQUIREMENTS AND REPOSITORY BENEFITS FOR LIMITED RECYCLING}

It is well established that fast spectrum systems have several favorable characteristics for repeated recycle of transuranic (TRU) materials. In particular, the neutron balance is significantly more favorable than thermal spectrum transmutation [19], facilitating effective management of the TRU inventory. Also, the generation of higher actinides is suppressed (by high fission-to-capture ratios), avoiding potential fuel handling difficulties. [20] Furthermore, the conventional fast reactor technology options rely on remote fuel fabrication allowing short processing times and "dirty" fuel materials. [20] Thus, fast reactor fuel cycles are designed to employ full recycle of the TRU with only the processing wastes going to geologic disposal.

One of the requests raised at the ANTT Subcommittee Meeting in February 2004 was to clarify the fast burner power capacity that would be required to consume the key transuranics produced by continued operation of once-through LWRs. This issue is addressed in Section V.1; the impact of future advances in discharge burnup and/or thermal efficiency of thermal reactors is considered.

As shown in Section III, a fully closed fuel cycle results in large repository benefits for the equilibrium condition. However, it is important to note that achievement of this loading benefit requires many recycles passes. On the other hand, the fast spectrum should yield some favorable transmutation behavior (e.g., less build-up of higher actinides) even in the early recycles. Therefore, it was deemed important to consider the repository loading benefits for limited recycle in a fast reactor. A scoping study analogous to the limited thermal recycle evaluation is described in Section V.2.

\section{V.1. Fast Reactor Resource Requirements}

First, the case of a sustained equilibrium with the existing LWR (enriched uranium) fuel cycle is addressed. At discharge, commercial LWR spent fuel at $50 \mathrm{GWd} / \mathrm{MT}$ burnup contains 5.3 wt. \% fission products compared to a transuranic (TRU) content of $1.4 \%$. Thus, any pure burner system must comprise $1.4 / 5.3=27 \%$ the power capacity of the LWR enterprise that is being supported. The variation of TRU content with burnup is given in Table V.1. Because the plutonium content saturates for high burnup LWR fuels, the ratio decreases and only a $18 \%$ burner fraction is required for the $100 \mathrm{GWd} / \mathrm{MT}$ case.

Table V.1. Variation of Burner Fraction with LWR Burnup.

\begin{tabular}{|c|c|c|c|}
\hline $\begin{array}{c}\text { LWR Fuel Burnup, } \\
\text { GWd/MT }\end{array}$ & $\begin{array}{c}\text { Discharge FP } \\
\text { Fraction, \% }\end{array}$ & $\begin{array}{c}\text { Discharge TRU } \\
\text { Fraction, } \%\end{array}$ & $\begin{array}{c}\text { Pure Burner } \\
\text { Ratio, \% }\end{array}$ \\
\hline 33 & 3.5 & 0.98 & 28 \\
\hline 50 & 5.3 & 1.42 & 27 \\
\hline 100 & 10.6 & 1.92 & 18 \\
\hline
\end{tabular}

The burner fractions in Table V.1 assume both 1) that the LWR and burner systems operate at the same thermal efficiency (mass consumption proportional to thermal power) and 2) that the burner systems does not create any new TRUs (i.e., employs a nonuranium fuel form). Given that modern fast reactor designs yield a higher thermal efficiency (e.g, PRISM design at 38\%) than conventional LWRs, an increased capacity 
of fast reactors would be required to consume the desired materials (by roughly a factor of $38 / 33=1.15$ ). Thus, the capacity of efficient fast burners would increase to $20-30 \%$ of the supported LWR capacity. Conversely, modern thermal gas reactor designs target a thermal efficiency of $47 \%$, reducing the TRU production for a given capacity. This would reduce the required capacity of pure burner fast reactors to $15 \%$ in the high burnup (100 GWd/MT) case consistent with the NGNP design burnup levels.

When fertile fuel is utilized, additional TRUs are created requiring additional fissions for their destruction; this results in higher fast reactor capacity requirements by roughly a factor of $1 /(1-C R)$, where CR is the TRU conversion ratio. Using conventional fuel enrichment, the conversion ratio (CR) of a fast burner reactor is limited to 0.5 , doubling the fast reactor capacity requirements compared with the pure burner. In recent AFCI studies, low conversion ration fast burner designs with $\mathrm{CR}=0.25$ have been developed. The safety and economic performance of these higher enrichment ( 50\% TRU/HM) designs has been evaluated in Ref. 21 and 22 respectively. At $\mathrm{CR}=0.25$ and 100 GWd/MT gas reactor burnup, a burner fraction of roughly $20 \%$ would be required at equilibrium.

The discussion above has focused on the relative power requirements for a burner reactor sector to support a given LWR once-through generation capacity. A brief comparison of typical plant size and mass flow rates is also useful. Based on Table V.1, a typical LWR operating at $90 \%$ capacity factor with $50 \mathrm{GWd} / \mathrm{MT}$ burnup and 33\% thermal efficiency would produce $20 \mathrm{MT} /$ year of spent fuel, of which $280 \mathrm{~kg}$ would be TRU. Based on Ref. 23, a single fast burner module ( $840 \mathrm{MWt}, 320 \mathrm{MWe}$ ) operating at $85 \%$ capacity factor with $\mathrm{CR}=0.25$ and 38\% thermal efficiency would consume 193 $\mathrm{kg} /$ year of TRU. Thus, three fast burner modules are required to "support" every two large LWRs, with a total fast reactor capacity of $\sim 45 \%$ the LWR capacity. As noted above, this capacity could be reduced to as low as $20 \%$ using higher burnup, higher efficiency thermal reactors.

Another approach to reduce the fast reactor capacity is the use of LWR multi-recycle in a 'first tier' to partially consume the TRU inventory. This could reduce the mass of TRU which must be consumed by the fast reactor (FR) burners and, consequently, reduce the number of transmuters which must be constructed. For a conventional fast burner system $(\mathrm{CR}=0.5)$, the variation of FR system capacity needed to "support" the partial and deep burnup LWR is summarized in Table V.2.

These results indicate that limited MOX recycle (two passes) or limited TRU recycle in CORAIL consume roughly half the TRU, and thus significantly reduce the fast reactor ratio. By combining this approach with the low conversion ratio fast reactor design and high burnup, high efficiency thermal systems, it may be possible to reduce the required fast power reactor fraction to $10 \%$, with another $10 \%$ thermal reactor transmutation sector supporting the base enriched uranium thermal reactors.

The last row of Table V.2 shows a multi-recycling (of Pu) concept that effectively provides a 76\% deep burnup of the TRU [25]. Although the deep burnup approach provides nearly a factor of 5 reduction to the required capacity of fast spectrum transmuters compared with the single-tier approach, the fuel handling indices and associated dose rates are roughly an order of magnitude greater. In addition, plutonium 
Table V.2. Fast Reactor Infrastructure Comparison for Multi-tier Options.

\begin{tabular}{|l|c|}
\hline \multicolumn{1}{|c|}{ Fuel Cycle Scenario } & $\begin{array}{c}\text { Fraction of Commercial Sector } \\
\text { (FR Power/Commercial Power) }\end{array}$ \\
\hline Single Tier [AFCI 2001, 24] & 0.576 \\
\hline Double MOX Recycle [24] & 0.304 \\
\hline Double CORAIL-TRU Recycle [25] & 0.351 \\
\hline Triple CORAIL-TRU Recycle [25] & 0.311 \\
\hline CORAIL-Pu Multi-Recycle [25] & 0.117 \\
\hline
\end{tabular}

Note: These results are for a $C R=0.5$ fast spectrum system. The power fraction would be reduced by $a$ factor of 2 at $C R=0.0$, and a factor of 1.5 at $C R=0.25$.

separation would be required to employ this strategy. For these reasons, the partial burn LWR strategies are considered more desirable for AFCI applications.

The specification of the FR fraction for a dynamic fuel cycle strategy is more complex because the initial loading and operating inventory of a fast reactor system is quite high. For perspective, 1 GWe capacity of FR burners $(C R=0.5)$ would require an equilibrium make-up feed of less than $400 \mathrm{~kg} /$ year. However, more than $10 \mathrm{MT}$ of TRU would be required to start-up this capacity. Thus, the initial inventory requirement embodies more than 25 years of external TRU inventory requirements once the recycle system is operating. This large inventory of TRU is not consumed and remains at the end of reactor life; however, it is contained within the fast reactor fuel cycle and no longer resides in the spent fuel waste inventory.

Therefore, the TRU management goals must be clearly defined to develop a favorable dynamic strategy. If the goal is to stabilize the total TRU inventory, the above equilibrium reactor ratios must be achieved as quickly as possible. Timing will be dictated by the significant processing requirements to recover and fabricate the initial inventory for each FR system. However, if the goal is only to stabilize the TRU waste inventory, an extended period at much smaller FR ratio could be utilized. Ideally, all new LWR spent fuel would be processed and first used as makeup feed for burner FRs and then accumulated as the initial inventory to start new FR systems. In this manner, the FR ratio would very slowly increase until the equilibrium ratio was achieved, at which point all LWR recovered TRU would be used as make-up.

Thus, for the dynamic situation, the starting FR power fraction of $0 \%$ and the endpoint FR power fraction at the equilibrium level are defined. However, the rate at which the FR power fraction must increase will depend on overall fuel cycle objectives. The large initial inventory of fast reactor systems makes then quite effective in tying up large quantities of TRU. Thus, a small fraction could be used to simply remove the material from the waste stockpile. However, the equilibrium fraction will be required to stabilize the total TRU inventory. 


\section{V.2. Repository Benefits for Limited Fast Reactor Recycle}

In Refs. 1 and 2, the effectiveness of limited homogeneous recycling of plutonium, neptunium, and americium in LWRs for improving the repository performance relative to a once-through fuel cycle was investigated. The recycled transuranics were loaded into fuel pins in LWR assemblies, and the transuranics for subsequent recycle were derived solely from the previous discharge (serial recycle, without blending). For each recycle stage, the processing losses go to permanent disposal, along with the curium separated for the LWR recycle scheme (to avoid higher actinide build-up). In the final recycle stage, the spent fuel assemblies are directly disposed. Based on these assumptions, the repository loading benefits were evaluated [1] for up to five recycles. In this section, a similar approach will be applied for recycle in a fast burner reactor. The computational methods are briefly described in Section V.2.a, and the repository loading benefits are estimated in Section V.2.b. Finally, results are compared to the LWR limited recycling results in Section V.2.c.

\section{V.2.a. Fast Reactor Fuel Cycle Analysis Computation Methods}

For this study, the low conversion ratio fast burner design developed in Ref. 23 was utilized; the compact design configuration utilizes high enrichment fuel ( $50 \%$ TRU/HM) in a low fuel volume fraction configuration to achieve a conversion ratio of $\sim 0.25$. For the initial core loading, the transuranics recovered from conventional LWR spent fuel (50 GWd/MT burnup) with a five year cooling time were used. For subsequent recycles, all the TRUs are recovered from the previous recycle, except for $0.1 \%$ processing losses. Curium separation is not employed as higher actinide generation is not expected to be problematic for fast reactor recycle.

The equilibrium cycle mass flows were calculated using the REBUS-3 fuel cycle code. [26] For each recycle, all fuel is composed from the discharge composition of the previous recycle with a three year delay time (2 years cooling and 1 year separations and fabrication). The transuranics enrichment is determined to allow criticality for the specified six month cycle based on the equilibrium (batch-averaged) compositions; the remainder of the fuel is composed of uranium, also with the isotopic mixture recovered from the previous recycle. The compact configuration utilizes two enrichment zones to control the radial power peaking.

The REBUS-3 flux calculations were performed using a three-dimensional (hexagonal-Z) nodal diffusion methods and a twenty-one energy group structure. The depletion calculation utilizes burnup chains spanning the range from U-234 to Cm-246. The regional multigroup cross sections were generated using $\mathrm{MC}^{2}-2$ for each enrichment zone using the first recycle (LWR TRU feed) fresh fuel isotopic composition; the same cross section set, developed in Ref. 23, was used for the subsequent recycles. Previous studies have demonstrated the adequacy of this approach to generate cross section data for burner cores and compute accurate flux distributions.[25]

\section{V.2.b. Fast Reactor Limited Recycle Results}

As described in Section V.2.a, the initial fissile feed for the fast burner reactor is transuranics separated from conventional LWR spent fuel (50 GWd/MT) with five years cooling. The single assembly mass flows for the first five recycles are given in Table V.3. 
For this particular burner design, roughly $20 \%$ of the heavy metal is consumed each pass; roughly $25 \%$ of the TRU are consumed each pass. With a conversion ratio less than one, the Pu-239 production does not compensate its destruction. Therefore, a gradual degradation of the plutonium isotopics is observed, requiring the enrichment to increase from $49 \%$ TRU/HM in the first pass to $71 \%$ TRU/HM by the fifth recycle. In addition, some build-up of the higher actinides (Am and $\mathrm{Cm}$ ) is observed. However, these effects are much less severe than observed for recycle in the thermal system [2], where enrichment increases much larger than the $40 \%$ observed for fast recycle were required to maintain criticality in later recycles and very high actinides (e.g., Cf-252) were generated.

The repository loading benefits from limited fast reactor recycle were estimated using the mass flow results presented in Table V.3. For this study, analytical decay heat formulas were employed for cooling times between 100 and 1500 years. Decay heat contributions from Am-241, Pu-238, Pu-239, and Pu-240 were considered, including after disposal decay from their parent isotopes (e.g., Pu-241). As was done in Ref. 1, waste decay heats were normalized to the net energy produced by the transuranics prior to disposal. The normalized isotopic contributions to the repository heating are shown in Table V.4.

In the first pass, roughly $40 \%$ of the Am-241 chain is destroyed; combined with the additional power production, this results in a factor of 1.54 improvement in repository loading. Similar to the LWR recycle results, some penalty from the build-up of $\mathrm{Pu}-238$ is observed. However, the relative build-up of $\mathrm{Pu}-238$ is much less in the fast system (only $30 \%$, as compared to 2 times in the LWR) because the Np-237 and Am-241 capture reactions are less prevalent in a fast spectrum. Another step of roughly the same benefit to a total factor of 2.14 is observed for the second recycle. This trend continues up to a factor of 5.0 benefit at the fifth recycle, with Pu-238 consumption occurring in the later stages. While the marginal benefits for LWR recycles quickly decrease, there is a reduced sensitivity to isotopic degradation in the fast system. As shown in Table V.3, the enrichment increases are much smaller, which allows the fractional burnup of the TRU to be maintained with each additional recycle.

The effect of extending LWR spent fuel cooling time from 5 to 20 years was evaluated for the first fast reactor recycle. This allows Pu-241 to decay to Am-241, requiring an enrichment increase from 49 to 54\% TRU/HM. The higher enrichment reduces the Am-241 burnup in the first recycle to 35\%. The combined impact of higher enrichment and reduced burnup reduces the repository loading benefit to 1.41. Once again, the enrichment penalty is much more severe in a thermal spectrum (e.g., IMF benefit decreases from 1.8 to 1.2 for the same cooling time changes) because the reactivity difference between fissile and fertile isotopes is magnified in the thermal spectrum.

Finally, it is important to recognize that repository benefits can also be achieved using fast reactor systems with higher conversion ratios. For systems with conversion ratios greater than or equal to unity, the equilibrium concentration of the problematic higher actinides will be reduced (compared to LWR spent fuel) significantly. For this scoping study, the impact of higher conversion ratio was estimated by assuming all the additional TRU production was Pu-239 while the other TRU isotopes follow the burner core mass flow trends; this will slightly underestimate the higher actinide concentrations, but is 
Table V.3. Assembly Mass Flows (kg/year) for First Five Recycles in Fast Burner Reactor.

\begin{tabular}{|c|c|c|c|c|c|c|c|c|c|c|}
\hline & \multicolumn{2}{|c|}{ 1st Pass } & \multicolumn{2}{|c|}{ 2nd Pass } & \multicolumn{2}{|c|}{ 3rd Pass } & \multicolumn{2}{|c|}{ 4th Pass } & \multicolumn{2}{|c|}{ 5th Pass } \\
\hline & Charge & Discharge & Charge & Discharge & Charge & Discharge & Charge & Discharge & Charge & Discharge \\
\hline Am241 & 23.85 & 17.95 & 36.44 & 23.78 & 42.80 & 27.21 & 39.59 & 25.84 & 44.47 & 28.87 \\
\hline Am242m & 0.07 & 2.09 & 3.30 & 5.73 & 8.54 & 10.73 & 15.40 & 16.51 & 23.09 & 23.62 \\
\hline Am243 & 10.74 & 11.35 & 17.89 & 17.81 & 26.63 & 25.29 & 36.34 & 33.38 & 46.89 & 42.03 \\
\hline Americium & 34.66 & 31.40 & 57.63 & 47.31 & 77.97 & 63.23 & 91.34 & 75.72 & 114.46 & 94.51 \\
\hline $\mathrm{Cm} 242$ & 0.00 & 1.36 & 2.18 & 1.86 & 2.76 & 2.14 & 3.08 & 2.05 & 2.86 & 2.29 \\
\hline $\mathrm{Cm} 243$ & 0.07 & 0.10 & 0.16 & 0.18 & 0.27 & 0.24 & 0.39 & 0.28 & 0.41 & 0.30 \\
\hline $\mathrm{Cm} 244$ & 3.86 & 5.67 & 8.94 & 10.68 & 15.97 & 17.20 & 24.85 & 25.04 & 35.34 & 33.98 \\
\hline $\mathrm{Cm} 245$ & 0.29 & 0.92 & 1.47 & 2.17 & 3.24 & 3.92 & 5.65 & 6.16 & 8.69 & 8.83 \\
\hline Curium & 4.22 & 8.05 & 12.75 & 14.89 & 22.24 & 23.50 & 33.97 & 33.53 & 47.30 & 45.41 \\
\hline Neptunium & 33.03 & 18.55 & 28.49 & 16.11 & 23.44 & 13.33 & 18.66 & 10.64 & 14.61 & 8.41 \\
\hline Pu238 & 16.44 & 21.37 & 32.97 & 31.77 & 46.47 & 38.79 & 54.62 & 41.54 & 57.08 & 42.44 \\
\hline Pu239 & 333.33 & 202.12 & 313.38 & 189.48 & 278.14 & 169.65 & 239.85 & 148.33 & 204.76 & 128.16 \\
\hline $\mathrm{Pu} 240$ & 158.37 & 147.34 & 229.41 & 198.03 & 291.92 & 241.49 & 342.81 & 276.13 & 382.77 & 303.19 \\
\hline $\mathrm{Pu} 241$ & 74.86 & 39.84 & 53.94 & 38.26 & 49.00 & 41.27 & 50.90 & 45.71 & 55.05 & 50.03 \\
\hline $\mathrm{Pu} 242$ & 46.83 & 44.76 & 70.28 & 62.74 & 93.25 & 81.20 & 116.19 & 99.55 & 139.18 & 118.44 \\
\hline Plutonium & 629.83 & 455.43 & 699.99 & 520.28 & 758.78 & 572.41 & 804.36 & 611.26 & 838.84 & 642.27 \\
\hline U234 & 0.14 & 0.49 & 0.50 & 1.01 & 0.97 & 1.54 & 1.47 & 1.99 & 1.88 & 2.30 \\
\hline U235 & 5.90 & 2.67 & 2.56 & 1.25 & 1.19 & 0.71 & 0.67 & 0.53 & 0.49 & 0.50 \\
\hline U236 & 4.41 & 4.19 & 4.07 & 3.59 & 3.48 & 2.99 & 2.92 & 2.50 & 2.39 & 2.07 \\
\hline U238 & 718.06 & 641.08 & 624.26 & 557.20 & 542.17 & 483.65 & 476.86 & 424.80 & 410.27 & 365.09 \\
\hline Uranium & 728.51 & 648.43 & 631.38 & 563.04 & 547.80 & 488.88 & 481.91 & 429.82 & 415.02 & 369.96 \\
\hline Am-241 Chain & 98.99 & 58.71 & 91.85 & 64.21 & 95.05 & 72.40 & 96.15 & 77.71 & 108.22 & 87.73 \\
\hline TRU & 701.73 & 513.43 & 798.86 & 598.60 & 882.43 & 672.47 & 948.33 & 731.16 & 1015.21 & 790.59 \\
\hline HM & 1430.24 & 1161.86 & 1430.24 & 1161.64 & 1430.24 & 1161.35 & 1430.24 & 1160.98 & 1430.24 & 1160.55 \\
\hline TRU/HM Enrichment, \% & 49 & & 56 & & 62 & & 66 & & 71 & \\
\hline
\end{tabular}


Table V.4. Normalized Isotopic Decay Heat Contributions (Watt-years/GWd) ${ }^{\mathrm{a}}$ for LWR Spent Fuel and First Five Recycles in Fast Burner Reactor.

\begin{tabular}{|l|r|r|r|r|r|r|}
\hline & \multicolumn{1}{|c|}{$\mathbf{U O}_{\mathbf{2}}$} & \multicolumn{1}{c|}{ 1st pass } & 2nd pass & 3rd pass & 4th pass & 5th pass \\
\hline $\mathrm{Am}-241$ & 1951.7 & 1052.7 & 689.1 & 498.7 & 360.9 & 281.9 \\
\hline $\mathrm{Pu}-238$ & 203.6 & 255.8 & 230.8 & 184.1 & 135.8 & 98.8 \\
\hline $\mathrm{Pu}-239$ & 320.1 & 177.3 & 101.4 & 59.6 & 36.1 & 22.1 \\
\hline $\mathrm{Pu}-240$ & 535.2 & 463.3 & 385.4 & 313.1 & 252.5 & 200.2 \\
\hline Sum & 3010.7 & 1949.1 & 1406.7 & 1055.6 & 785.3 & 603.0 \\
\hline$\%$ Am-241 & $64.8 \%$ & $54.0 \%$ & $49.0 \%$ & $47.2 \%$ & $46.0 \%$ & $46.8 \%$ \\
\hline $\begin{array}{l}\text { Estimated Benefit } \\
\text { Relative to UO } \\
\text { Direct Disposal }\end{array}$ & & $\mathbf{1 . 5 4}$ & $\mathbf{2 . 1 4}$ & $\mathbf{2 . 8 5}$ & $\mathbf{3 . 8 3}$ & $\mathbf{4 . 9 9}$ \\
\hline
\end{tabular}

${ }^{a}$ Decay heat integrated from 100 to 1,500 years after spent fuel discharge and normalized to net energy produced by recycled transuranics prior to disposal. Normalization factors are: $\mathrm{UO}_{2}, 51 \mathrm{GWd} / \mathrm{MTHM} ; 1^{\text {st }}$ pass, $2104 \mathrm{GWd} / \mathrm{MTHM} ; 2^{\text {nd }}$ pass, $3451 \mathrm{GWd} / \mathrm{MTHM} ; 3^{\text {rd }}$ pass, $5263 \mathrm{GWd} / \mathrm{MTHM} ; 4^{\text {th }}$ pass, 7599 GWd/MTHM; $5^{\text {th }}$ pass, $10,728 \mathrm{GWd} /$ MTHM.

considered adequate for modeling internal conversion regions that typically have at least 95\% Pu-239 at discharge. This approach significantly increases the Pu-239 decay heat, but as shown in Table V.4 this is a minor component. With this approximation, the repository benefit decreases from 1.55 to 1.43 in the first cycle, and down to 3.53 after the fifth recycle. Because the $\mathrm{CR}=1$ reactor does not consume TRU, the fast reactor power fraction would have to increase from 19 to $31 \%$ in this scenario (for $\mathrm{N}=5$ ).

\section{V.2.c. Comparison to LWR Recycle Results}

In this section, the repository benefits for limited fast reactor recycle (Section V.2.b) are compared to the LWR limited recycle results. It is important to note that explicit repository thermal calculations were performed for the LWR recycle cases [1], whereas the repository benefits obtained here were estimated from the fast reactor assembly mass flows (Table V.3). It has been found that utilizing mass flow data only, repository benefits can be estimated to within $\sim 5 \%$, but more detailed decay heat and repository thermal analysis would be required for better accuracy.

The estimated repository benefit as a function of number of recycles is shown in Figure V.1 for the three thermal recycle cases and the $\mathrm{CR}=0.25$ and $\mathrm{CR}=1$ fast reactor cases. As shown in Section V.2.b, the fast reactor achieves roughly a 50\% loading benefit for a single recycle, with sustained benefits thereafter. This is significantly better than the two LWR MOX options that yield at most a loading improvement of 1.2 for a single recycle of transuranics. However, the observed benefit is less than the 1.8 factor achieved by LWR IMF, which is attributed to the use of non-uranium fuel. A similar benefit would be expected from a $\mathrm{CR}=0$ fast system.

The results in Figure V.1 are for 5 years cooling before LWR spent fuel separation and recycle. If the cooling time was extended to 20 years, the single recycle IMF benefit would decrease to 1.2, but the single recycle fast burner benefit would only decrease to 1.4. Thus, for older fuel the fast burner would provide a significantly higher benefit for the initial recycles because it is less sensitive to the fissile Pu-241 decay. In addition, the 


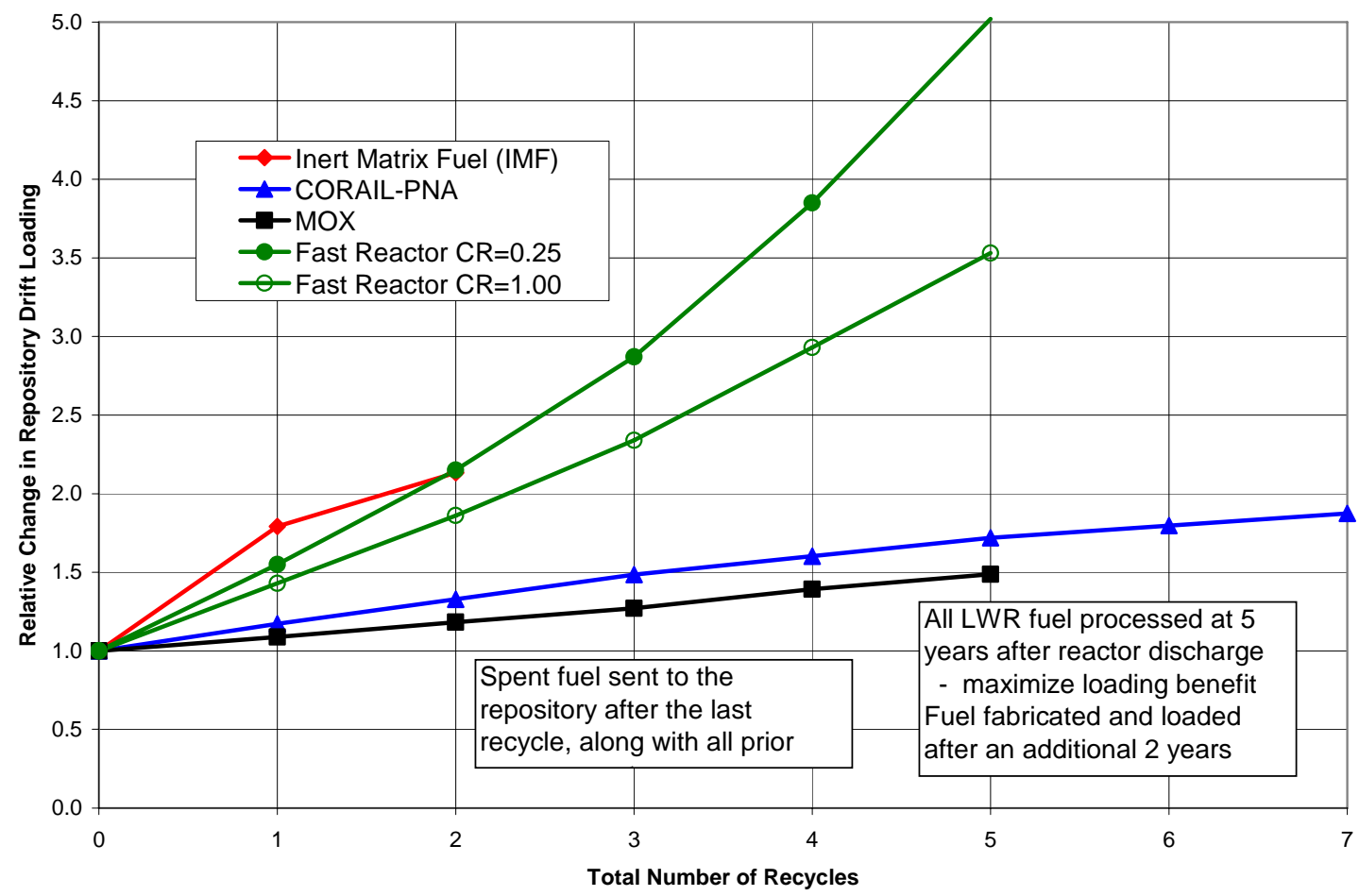

Figure V.1. Repository Benefits for Fast and Thermal Limited Recycle.

fast reactor recycle benefit does not saturate at $\sim 2$ as observed for the thermal recycle cases. As discussed in the previous section, the required enrichment increases for each subsequent recycle are much smaller in the fast system, leading to this behavior.

Because the fast reactor recycle system employs remote fuel processing and fabrication, it may be possible to shorten the spent fuel cooling and re-fabrication delay times. In practice, this would mean that each recycle stage could be accomplished in a shorter time period. For this study, a three year turn-around for fast reactor recycle was assumed, compared to seven years for the LWR; for typical core residence time this translates to a $\sim 30 \%$ reduction in time required for each recycle pass. This behavior is illustrated in Figure V.2 where the recycle interval differences between the fast and thermal systems are applied. Therefore, another potential benefit for fast reactor recycle is that the loading benefits could be achieved more quickly. 


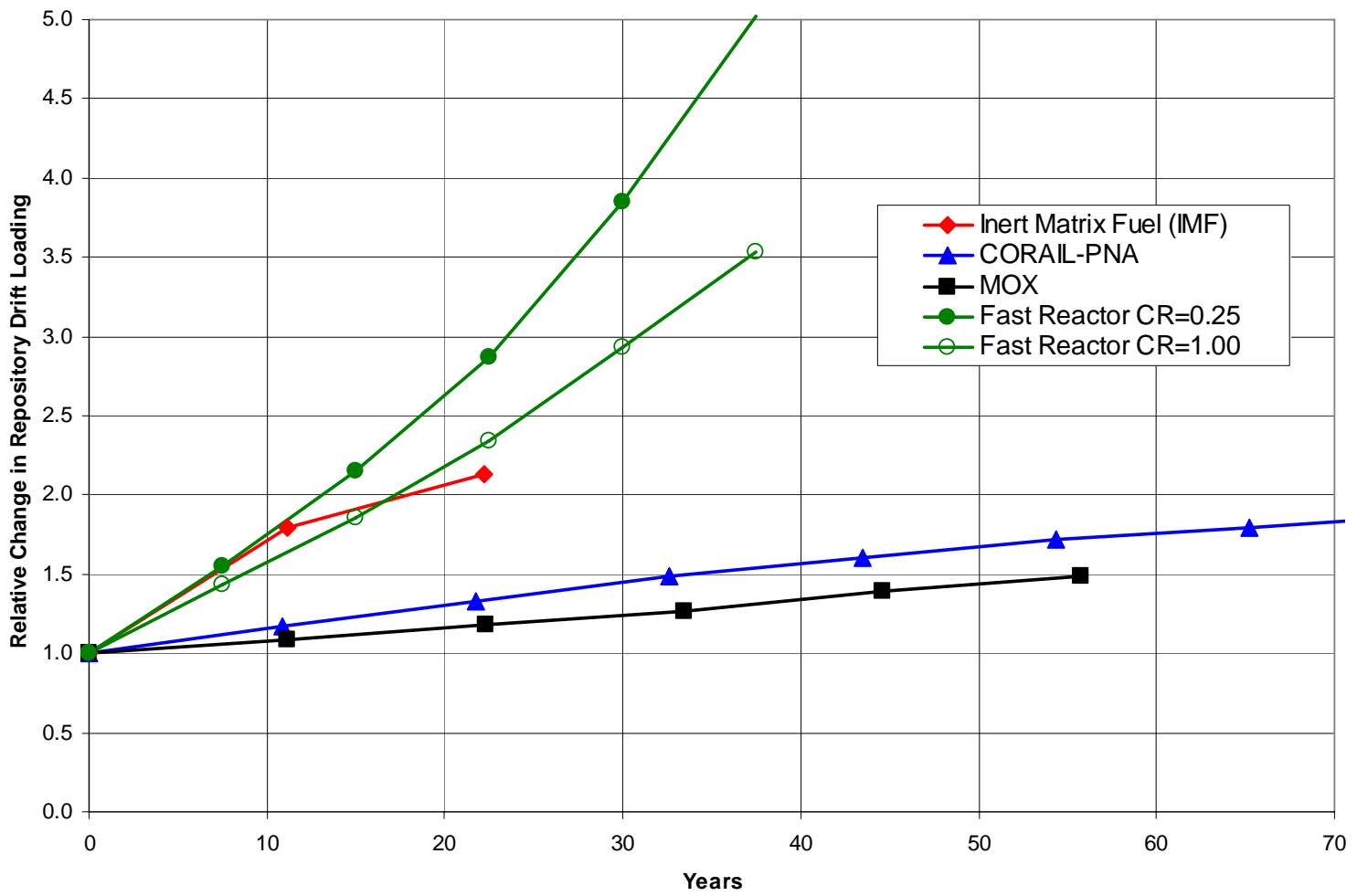

Figure V.2. Repository Benefits for Fast and Thermal Limited Recycle: Time Dependence. 


\section{TOPICS FOR FUTURE ANALYSES}

As a result of the efforts in FY04, the effect on the thermal loading of a geologic repository from limited recycle in LWRs, as well as the impact of various operational changes involving delay of waste placement and other options, is now fairly clearly understood. However, there are still viable options that were not analyzed that could potentially provide a large benefit to a geologic repository. These options all use continuing recycle of the recovered actinides, and as discussed in Ref. 1, only such systems offer the possibility of making large increases in repository space utilization. In addition, there are other once-through or limited-recycle thermal reactor options which may or may not offer benefits to the repository, such as gas reactor technology. In FY05, many of these options will be evaluated to complete the understanding of potential benefits from AFCI technologies to space utilization in a geologic repository.

A related issue which has become more important lately, and is the subject of the latest request from the ANTT subcommittee, concerns the dose rate associated with releases from a repository. While preliminary work has already been done on this issue, probably sufficient to answer the questions posed by the ANTT subcommittee, it is clear that more work will be required in this area as well. Preliminary estimates indicate that there is the potential to lower the estimated peak dose rate below $15 \mathrm{mrem} / \mathrm{year}$ for all times with the use of certain AFCI technologies. This is true even for some increased usage of repository space, estimated to be about a factor of 5 or so at this time. Further analyses using performance assessment models will need to be done to quantify the impact of the various AFCI scenarios, similar to what was done for the thermal heat load issue. Given the upcoming application for a license for a repository at Yucca Mountain, cooperation with DOE OCRWM would appear to be essential to reaching a mutual understanding on the capabilities of AFCI technologies to benefit a geologic repository.

Another important focus of AFCI Systems Analysis in FY05 will be the evaluation of proliferation resistant fuel cycle features. Recent external feedback has encouraged focus on the weakest links of the postulated fuel cycle options; thus, particular attention will be given to the role of intrinsic characteristics for the separated materials. An analysis similar to the proliferation characteristics evaluation in Section IV will be conducted. However, the focus will be on the initial recycle fuel (from LWR spent fuel) where the radiation levels will be lowest. A variety of elemental separation strategies will be investigated including $\mathrm{Pu}, \mathrm{Pu}+\mathrm{Np}, \mathrm{Pu}+\mathrm{Np}+\mathrm{Am}$, and all TRU recycle; and results will be compared to conventional reprocessing (PUREX, Pu recycle) technology. In addition, the fuel cycle impacts of including the higher actinides for LWR recycle will be evaluated. For example, the increased radiation levels will complicate fuel handling and fabrications, requiring additional protection and/or operational changes in the fuel cycle.

Finally it is noted that AFCI Systems Analysis work in FY05 will focus on the investigation of dynamic fuel cycle scenarios. As discussed in Section V.1, the dynamic fuel cycle inventories can behave quite differently than the equilibrium studies. The scenario studies are being conducted to support the March 2005 Report to Congress; dynamic systems analysis of key AFCI fuel cycle scenarios has been identified as an urgent priority to answer specific requests and complete definition of AFCI benefits and goals. The ultimate goal is to derive robust quantitative goals for the AFCI. The purpose of the systems dynamic analyses is to illustrate the behavior of key fuel cycle options and 
investigate the timing of key waste management parameters. The dynamic studies will clarify the time-dependent infrastructure (both storage and fuel cycle facilities) required for different fuel cycle technology and deployment options. 


\section{REFERENCES}

1. Wigeland, R. A. and Bauer, T. H., Repository Benefits of AFCI Options, ANL-AFCI129, Argonne National Laboratory (2004).

2. Stillman, J. A., Homogeneous Recycling Strategies in LWRs for Plutonium, Neptunium, and Americium Management, ANL-AFCI-124, Argonne National Laboratory (2004).

3. Kim, T. K, Stillman, J. A., and Taiwo, T. A., Assessment of TRU Stabilization in PWRs, Argonne National Laboratory, ANL-AAA-020, August, 2002.

4. Stillman, J. A., Mixed-Oxide Assembly Design for Series 1 Transmutation, Argonne National Laboratory, ANL-AFCI-086, July, 2003.

5. Taiwo, T. A., Kim, T. K., and Salvatores, M., Feasibility Study of a Proliferation Resistant Fuel Cycle for LWR-Based Transmutation of Transuranics, Argonne National Laboratory, ANL-AAA-027, August, 2002.

6. Del Cul, Guillermo D., Spencer, Barry B., and Collins, Emory D., Fuel Cycle Advantages Resulting from the Significant Inventory of U. S. Spent Fuel, Global 2003, New Orleans, LA, USA, November, 2003.

7. "Geologic Repository Impact of the Separations Proposed In Phase 1 and Phase 2 of Processing Spent Nuclear Fuel," R.A. Wigeland and T.H. Bauer, AFCI Milestone Letter Report, March 31, 2004.

8. Wigeland, R. A., et al, Spent Nuclear Fuel Separations and Transmutation Criteria for Benefit to a Geologic Repository, Waste Management '04, Tucson, AZ, February 29-March 4, 2004.

9. Wigeland, R. A., et al, Repository Impact of LWR MOX and Fast Reactor Recycling Options, Global 2003, New Orleans, LA, USA, November 16-20, 2003.

10. Wigeland, R. A., et al, Repository Benefit Analysis - Series 1 Impact, ANL-AFCI089, Argonne National Laboratory (2003).

11. SINDA/G, Network Analysis, Inc., Chandler, AZ, 2003.

12. J.A. Stillman, PWR spent fuel characteristics, private communication.

13. MCNP - A General Monte Carlo N-Particle Transport Code, Version 4B, Los Alamos National Laboratory, LA-12625-M.

14. Croff, A. G., ORIGEN2 - A Revised and Updated Version of the Oak Ridge Isotope Generation and Depletion Code, Oak Ridge National Laboratory, ORNL-5621.

15. Annex: Attributes of Proliferation Resistance for Civilian Nuclear Power Systems, Nuclear Energy Research Advisory Committee, October, 2000.

16. Mark, J. Carson, Explosive Properties of Reactor-Grade Plutonium, Sceince and Global Security, 1993, Volume 4, pp. 111-128. 
17. Literature Review of the Lifetime of DOE Materials: Aging of Plastic Bonded Explosives and the Explosives and Polymers Contained Therein, Amarillo National Resource Center for Plutonium, ANRCP-1998-12, September, 1998.

18. Raymond N. Rogers and Joan L. Rogers (Los Alamos), "Explosives Science,” http://home.att.net/ rnrogers.

19. Hill, R. N., Comparison of Fast Reactor Transmutation Potential, Argonne National Laboratory, ANL-AFCI-115, September, 2003.

20. Hill, R. N., Summary Report and Downselection Recommendations for Multi-tier Transmutation Strategies, Argonne National Laboratory, ANL-AFCI-060, December 2002.

21. Cahalan, J. E. and Dunn, F. E., Safety Analysis of an Unprotected Loss-of-Flow Accident in a Compact Low-Conversion Ration Fast Burner Reactor, Argonne National Laboratory, ANL-AFCI-107, September 2003.

22. Hoffman, E. A. Hoffman, Estimated Cost for Low Conversion Ratio Burners, Argonne National Laboratory, ANL-AFCI-118, June 2004.

23. Smith, M. A. and Hill, R. N., Development and Analysis of a Compact LowConversion Ratio Fast Burner Reactor, Argonne National Laboratory, ANL-AFCI084, June, 2002.

24. Candidate Approaches for an Integrated Nuclear Waste Management Strategy Scoping Evaluations, AAA Program Report, AAA-PDO-GEN-01-0051, November 2001.

25. Stillman, J. A., Effect of Thermal-Spectrum Transmuter Deep Burnup of Transuranics on Fast-Spectrum Transmuter Performance, Argonne National Laboratory, ANLAAA-042, September, 2002.

26. Toppel, B. J., A User's Guide to the REBUS-3 Fuel Cycle Analysis Capability, Argonne National Laboratory Report, ANL-83-2 (1983). 


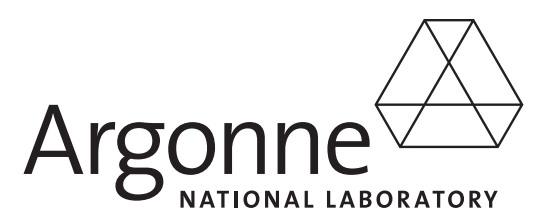

Nuclear Engineering Division

Argonne National Laboratory

9700 South Cass Avenue, Bldg. 208

Argonne, IL 60439-4842

www.anl.gov

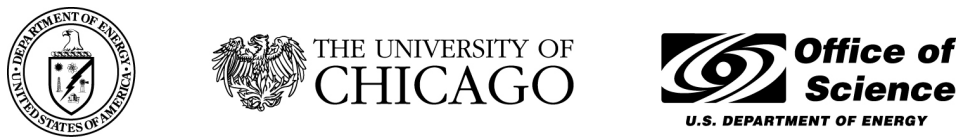

A U.S. Department of Energy laboratory managed by The University of Chicago 